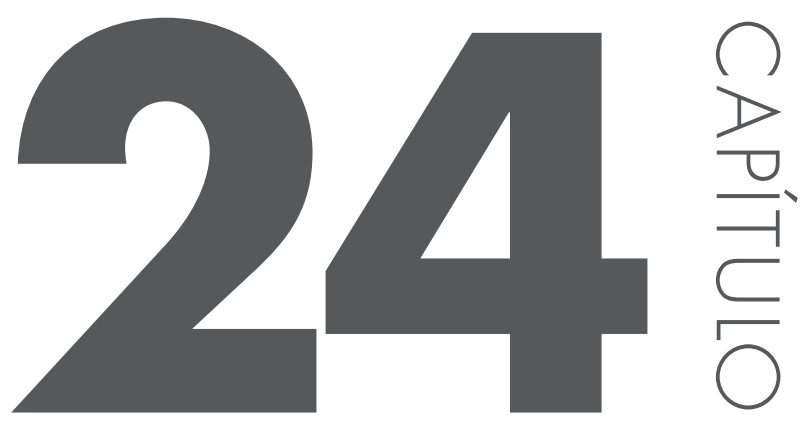

\title{
MÉTODOS IMUNOLÓGICOS PARA A DETECC̣ÃO DE FUNGOS TOXIGÊNICOS E MICOTOXINAS EM GRÃOS, ALIMENTOS E RAC̣ÕES
}

Elisabete Yurie Sataque Ono Jaqueline Gozzi Bordini Aline Myuki Omori Melissa Tiemi Hirozawa Mario Augusto Ono

\subsection{INTRODUC̣ÃO}

Os produtos agrícolas, devido à sua alta qualidade nutricional, constituem um substrato suscetível à contaminação por fungos toxigênicos ${ }^{1}$. Essa contaminação, além de reduzir a produtividade e a qualidade dos grãos, acarretando perdas econômicas, podem causar efeitos tóxicos em seres humanos e animais devido à produção de metabólitos secundários tóxicos, 
denominados micotoxinas ${ }^{2}$. A contaminação por micotoxinas pode ocorrer no campo, durante a colheita, no transporte e no armazenamento dos grãos e depende de fatores biológicos e ambientais ${ }^{3}$.

Os fungos toxigênicos envolvidos na contaminação da cadeia produtiva de grãos pertencem principalmente aos gêneros Fusarium, Penicillium e Aspergillus ${ }^{3,4}$. As micotoxinas de maior impacto econômico a contaminar produtos agrícolas em regiões de climas tropical e subtropical são as fumonisinas e as aflatoxinas, produzidas principalmente por Fusarium verticillioides e Fusarium proliferatum ${ }^{5}$, e por Aspergillus flavus Link e Aspergillus parasiticus Speare, respectivamente ${ }^{6,7}$.

A ocorrência de aflatoxinas e fumonisinas em produtos agrícolas é um problema reportado no mundo todo ${ }^{8-11}$. Devido à alta frequência e aos riscos à saúde associados às aflatoxinas e fumonisinas, diversos países estabeleceram ou reduziram os limites regulatórios para micotoxinas. Em 2003, ao menos 99 países possuíam alguma legislação para micotoxinas, o que representou um aumento de $30 \%$ em relação a $1995^{12}$. As legislações estão cada vez mais rigorosas, e os países exportadores de produtos agrícolas estão se adequando às novas exigências internacionais sobre os limites máximos tolerados para micotoxinas, visando à manutenção de seus produtos no mercado. No Brasil, o limite máximo para aflatoxinas era de $50 \mu \mathrm{g} / \mathrm{Kg}$ em milho e em outras matérias-primas ${ }^{13}$. Contudo, a Agência Nacional de Vigilância Sanitária (ANVISA), por meio da Resolução RDC n ${ }^{\circ}$ 07/2011, reduziu os limites máximos tolerados de aflatoxinas em milho e amendoim para 20 $\mu \mathrm{g} / \mathrm{Kg}$, além de estabelecer limites máximos para as fumonisinas em milho $(5.000 \mu \mathrm{g} / \mathrm{Kg})$ e para outras micotoxinas para as quais antes não existiam parâmetros no Brasil ${ }^{14}$.

Tendo em vista que a contaminação de produtos agrícolas por fungos toxigênicos e micotoxinas é difícil de evitar, um monitoramento contínuo de grãos, alimentos e rações por meio de métodos sensíveis e precisos é essencial para minimizar os efeitos tóxicos e as perdas econômicas.

Os métodos convencionais de identificação e detecção de fungos incluem o cultivo em diversos meios, exame microscópico e análises químicas de quitina, ergosterol ou metabólitos secundários. Com exceção do último, que inclui micotoxinas, os demais métodos apresentam baixa especificidade e reprodutibilidade e consomem muito tempo ${ }^{15}$. Os estudos de sistemática molecular, apesar de possuírem alta especificidade, também apresentam custo elevado ${ }^{16}$.

As micotoxinas são geralmente detectadas por meio de cromatografia líquida de alta eficiência (CLAE, do inglês, high performance liquid 


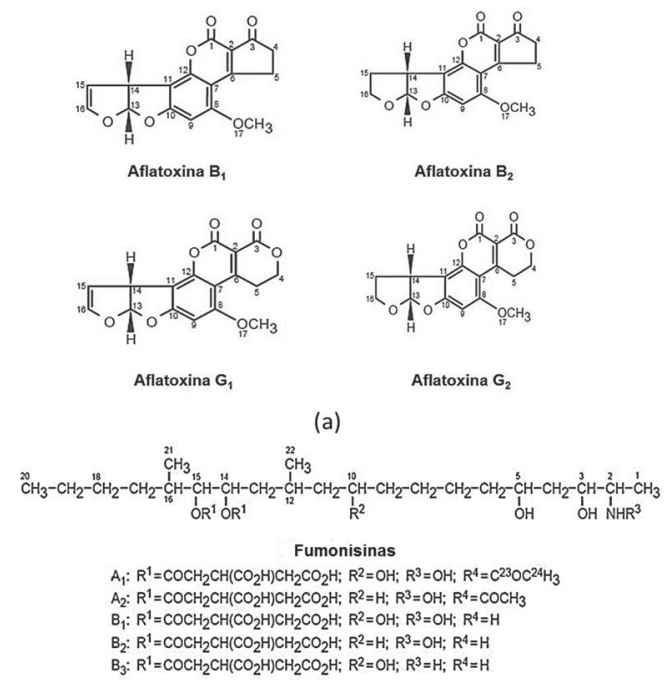

(b)

Figura 24.1 (a) Estrutura das aflatoxinas $B_{1}, B_{2}, G_{1}$ e $G_{2}$; (b) estrutura das fumonisinas $A_{1}, A_{2}, B_{1}, B_{2}$ e $B_{3}$. Fonte: CAST (2003) ${ }^{3}$, com permissão para a reprodução.

chromatography - HPLC), cromatografia gasosa e espectrometria de massa ${ }^{17,18}$. A cromatografia líquida acoplada a espectrômetro de massa (LCMS/MS) tem sido utilizada para a determinação simultânea de várias micotoxinas com baixos limites de detecção. Contudo, a necessidade de uma extensa pré-limpeza da amostra, o que aumenta os custos, a utilização de solventes e as limitações da análise in situ tornam necessária a utilização de técnicas alternativas ${ }^{17,19}$.

Os métodos imunológicos para a detecção de fungos toxigênicos e micotoxinas constituem técnicas alternativas promissoras. Esses métodos apresentam várias vantagens, como facilidade de operação, especificidade e alta sensibilidade, além de não requererem etapa de pré-limpeza da amostra, permitirem a análise simultânea de várias amostras, não utilizarem reagentes tóxicos e poderem ser realizados no campo ${ }^{15,20-23}$.

Neste capítulo, são abordados conceitos básicos relativos a anticorpos e antígenos, tipos de imunoensaios, imunoensaios para a detecção de Aspergillus spp. e Fusarium spp., assim como para a detecção de aflatoxinas e fumonisinas. 


\subsection{CONCEITOS BÁSICOS RELATIVOS A ANTICORPOS E ANTÍGENOS}

Os anticorpos, ou imunoglobulinas, são glicoproteínas produzidas pelos linfócitos B em resposta principalmente a patógenos como vírus, bactérias, fungos, protozoários e helmintos. Os linfócitos B podem produzir anticorpos contra praticamente qualquer antígeno. Há cinco classes de anticorpos: $\operatorname{Ig} G$, $\operatorname{IgM}, \operatorname{Ig} \mathrm{A}, \operatorname{IgD}$ e IgE. Nos ensaios imunológicos, geralmente são utilizados anticorpos IgG. Os sítios de ligação, localizados na extremidade N-terminal dos anticorpos, ligam-se a regiões dos antígenos denominadas epítopos. Os antígenos que induzem uma resposta imune são denominados imunógenos. Antígenos de baixa massa molecular que para induzir uma resposta imune precisam ser conjugados com moléculas carreadoras (proteínas como albumina bovina e ovalbumina) são denominados haptenos (Figura 24.2).

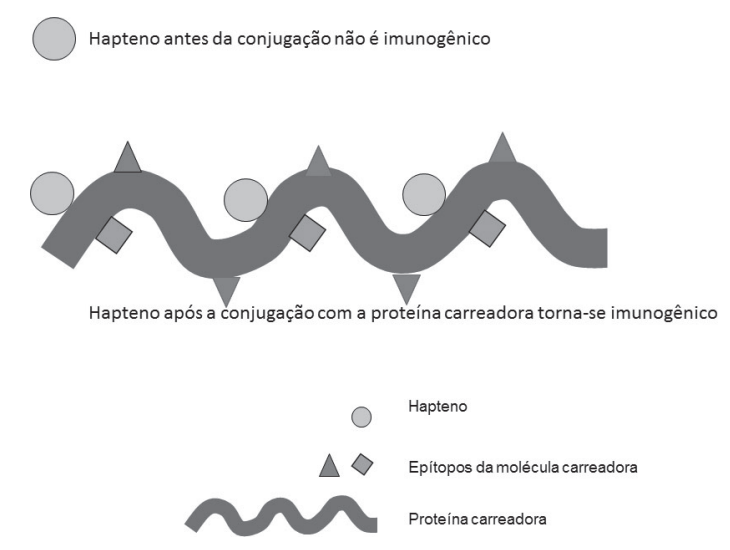

Figura 24.2 Sistema hapteno-molécula carreadora. A molécula de hapteno, devido à baixa massa molecular, não apresenta imunogenicidade. Porém, quando conjugada à molécula carreadora, torna-se imunogênica.

Devido à propriedade de interagir com antígenos com alta especificidade, os anticorpos podem ser utilizados como ferramentas para a detecção qualitativa ou quantitativa de diferentes moléculas. Os anticorpos podem ser produzidos em animais como coelhos, ratos e camundongos por meio da inoculação do animal com várias doses do antígeno e posterior purificação dos anticorpos do soro hiperimune. Embora a produção desses anticorpos, denominados policlonais, seja relativamente simples e de baixo custo, devido ao fato de ser resultante da ativação de vários clones de linfócitos $\mathrm{B}$ 
pode ocorrer reatividade cruzada com antígenos diferentes dos utilizados na imunização.

Os anticorpos monoclonais, por sua vez, são produzidos por meio da fusão de células B tumorais com células B de camundongos isogênicos e, embora sejam tecnicamente mais difíceis de serem produzidos, constituem reagentes homogêneos, de maneira que um determinado anticorpo monoclonal possui apenas um tipo de sítio de ligação ao antígeno e, consequentemente, liga-se a um único epítopo.

\subsection{TIPOS DE IMUNOENSAIOS}

Os ensaios imunoenzimáticos ELISA, do acrônimo enzyme linked immunosorbent assay, têm sido amplamente utilizados para a detecção de fungos toxigênicos e micotoxinas e baseiam-se na conjugação do antígeno ou do anticorpo com uma enzima. Nos ensaios em que se utilizam dois anticorpos, o anticorpo não marcado que se liga ao antígeno é denominado anticorpo primário, enquanto o anticorpo marcado com enzima que se liga ao anticorpo primário é denominado anticorpo secundário. Os principais tipos de ELISAs são o indireto, o competitivo direto (dc-ELISA), o competitivo indireto (ic-ELISA) e o ELISA sanduíche.

O ELISA indireto é uma técnica qualitativa e consiste na detecção da interação de um anticorpo primário não marcado com o antígeno imobilizado na microplaca. A ligação do anticorpo primário ao antígeno é detectada por meio de um anticorpo secundário marcado com uma enzima (Figura 24.3). Esse método é mais utilizado na detecção de anticorpos em amostra de soro para diagnóstico de doenças infecciosas.

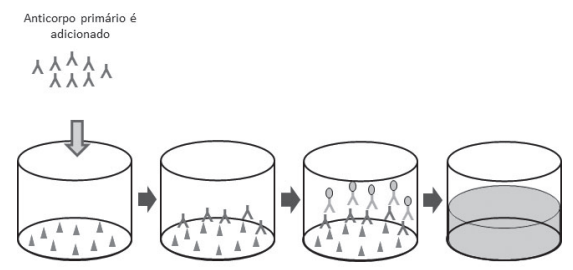

Figura 24.3 ELISA indireto. 0 anticorpo é adicionado à placa contendo antígeno imobilizado. Ao adicionar 0 anticorpo secundário marcado com enzima e posteriormente o substrato, a coloração desenvolvida será proporcional à ligação do anticorpo primário ao antígeno. 
No ELISA competitivo direto (dc-ELISA), a sensibilização da microplaca é realizada com o anticorpo específico, ocorrendo a competição entre o antígeno presente na amostra e o antígeno marcado com uma enzima pelo sítio de ligação do anticorpo. Assim, quanto maior a concentração de antígeno na amostra, menor será a ligação do antígeno marcado com o anticorpo ${ }^{24}$ (Figura 24.4).

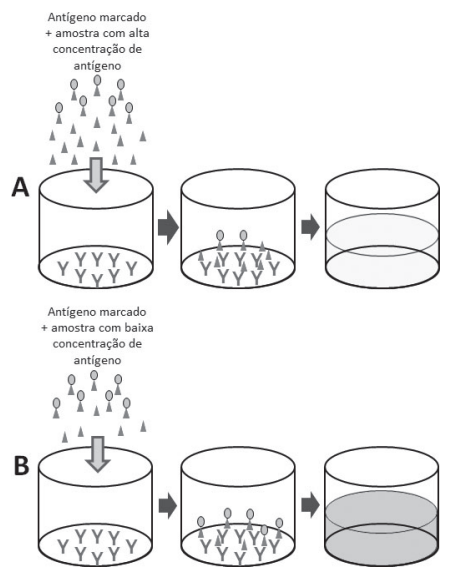

Figura 24.4 ELISA competitivo direto (dc-ELISA). Antígeno marcado com enzima é adicionado juntamente com as amostras contendo: (A) alta concentração de antígeno; ou (B) baixa concentração do antígeno a ser analisado. Quanto maior a concentração do antígeno na amostra, menor será a ligação do antígeno marcado aos anticorpos e, consequentemente, menor será a coloração da reação após a adição do substrato.

No ELISA competitivo indireto (ic-ELISA), a competição ocorre entre o antígeno imobilizado na microplaca e o antígeno presente na amostra, pelo sítio de ligação do anticorpo. A amostra contendo o antígeno é misturada ao anticorpo e então adicionada à microplaca. A ligação entre o anticorpo e o antígeno da placa será tanto menor quanto maior for a concentração de antígeno na amostra. Para detectar o anticorpo primário, utiliza-se um anticorpo secundário marcado com enzima. Quanto maior a concentração de antígeno na amostra, menor será a absorvância ${ }^{24}$ (Figura 24.5).

O ELISA sanduíche apresenta duas etapas. Na primeira etapa a amostra contendo o antígeno é adicionada à microplaca e ocorre a ligação com o anticorpo imobilizado. Na segunda etapa, é adicionado um segundo anticorpo marcado com enzima que se liga a um epítopo diferente no antígeno. 


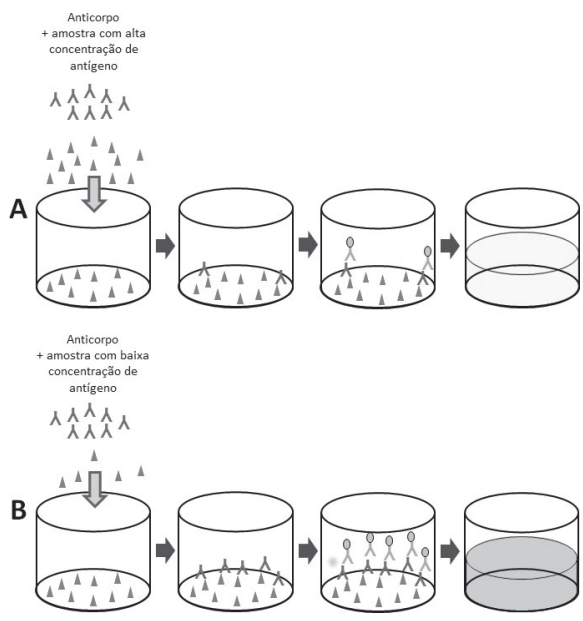

Figura 24.5 ELISA competitivo indireto (ic-ELISA). 0 anticorpo é adicionado juntamente com as amostras contendo: (A) alta concentração de antígeno; ou (B) baixa concentração do antígeno a ser analisado. Quanto maior a concentração do antígeno na amostra, menor será a ligação do anticorpo primário ao antígeno imobilizado na placa. Ao adicionar o anticorpo secundário marcado com enzima e posteriormente 0 substrato, a coloração desenvolvida será inversamente proporcional à concentração de antígeno na amostra.

Assim, após a adição do substrato, a absorvância será diretamente proporcional à concentração de antígeno presente na amostra ${ }^{24}$ (Figura 24.6).

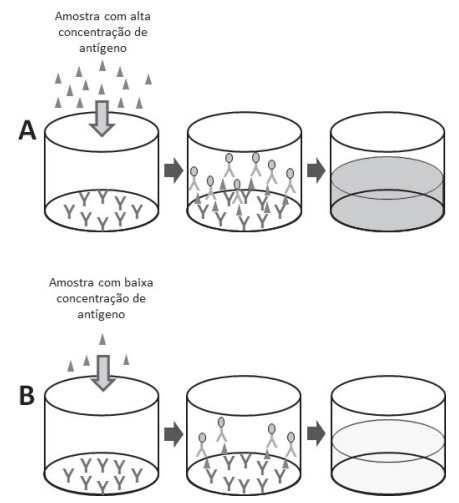

Figura 24.6 ELISA sanduíche. Amostras contendo: (A) alta concentração de antígeno; ou (B) baixa concentração do antígeno a ser analisado, são adicionadas à placa. Quanto maior a concentração do antígeno na amostra, maior será a ligação ao anticorpo de captura imobilizado na placa. Ao adicionar 0 anticorpo secundário marcado com enzima e posteriormente o substrato, a coloração desenvolvida será diretamente proporcional à concentração de antígeno na amostra. 
O desenvolvimento de um ELISA requer a determinação do limite de detecção ou sensibilidade e da especificidade do anticorpo para garantir resultados mais consistentes ${ }^{25}$.

A imunocromatografia, também chamada de teste de fluxo-lateral, baseia-se em uma membrana (geralmente de nitrocelulose) dividida em várias camadas, incluindo uma camada da amostra, uma camada do conjugado (anticorpo antimicotoxina conjugado com ouro), uma camada absorvente, além de uma zona teste e uma zona controle, que contêm a micotoxina conjugada a uma proteína e a um anticorpo secundário (antianticorpo), respectivamente. O extrato de uma amostra é adicionado à camada da amostra, fluindo para a camada do conjugado por capilaridade, continuando a migrar juntos ao longo da membrana, atingindo a zona teste e controle. Em uma amostra positiva, o anticorpo antimicotoxina conjugado com ouro coloidal irá se ligar à micotoxina presente na amostra e não estará livre para se ligar à micotoxina-proteína imobilizada na membrana. Portanto, não formará uma linha visível na zona teste. Por outro lado, em uma amostra negativa, o conjugado anti-micotoxina-ouro estará disponível para se ligar à micotoxina-proteína imobilizada e formará uma linha visível na zona teste. A zona controle será sempre visível, independentemente da presença ou ausência de micotoxinas, uma vez que o segundo anticorpo sempre irá capturar o conjugado antimicotoxina-ouro, indicando a validade do teste (Figura 24.7) ${ }^{23,26}$.

A imunocromatografia é um método rápido que fornece resultados em 5 a 15 minutos e é utilizada para a detecção qualitativa de micotoxinas principalmente na triagem de amostras. Recentemente, porém, foram descritos métodos imunocromatográficos semiquantitativos e quantitativos para a análise de micotoxinas em cereais ${ }^{27,28}$.

Os dipsticks são constituídos de uma tira de membrana de nitrocelulose com anticorpo específico antimicotoxina imobilizado. A tira é imersa

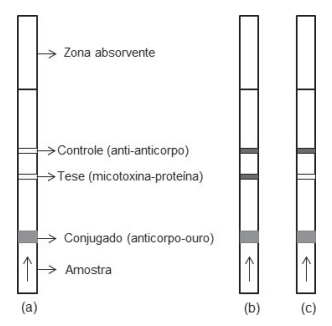

Figura 24.7 (A) Esquema de uma imunocromatografia para a detecção de micotoxinas; (B) detecção visual de uma amostra negativa e (C) positiva. 
inicialmente na solução contendo a amostra e o conjugado micotoxina-enzima para ocorrer a competição e em seguida na solução de substrato cromogênico. Quando a micotoxina está presente na amostra não ocorre o desenvolvimento de cor na área sensibilizada com o anticorpo antimicotoxina. Há também um controle que consiste numa área da tira sensibilizada com um anticorpo antienzima, que captura o conjugado micotoxina-enzima, promovendo o desenvolvimento de $\operatorname{cor}^{29}$. Alguns dispsticks, em vez de utilizarem conjugados enzimáticos e substratos cromogênicos, utilizam conjugados de anticorpos marcados com ouro coloidal ${ }^{30}$.

Os dipsticks são utilizados para detectar visualmente a presença de micotoxinas, fornecendo uma avaliação qualitativa (negativa/positiva) das amostras em aproximadamente 30 minutos. Contudo, estão disponíveis alguns leitores fotométricos portáteis para analisar eletronicamente os disptiscks, fornecendo resultados semiquantitativos ${ }^{31-34}$.

\subsection{IMUNOENSAIOS PARA A DETECC̣ÃO DE Aspergillus spp. E Fusarium spp.}

\subsubsection{Aspergillus spp.}

As espécies de Aspergillus são muito importantes economicamente, tanto pelos efeitos benéficos, devido à ampla utilização na síntese de produtos químicos, nas transformações biossintéticas e na produção de enzimas, quanto pelos efeitos prejudiciais, devido à deterioração de alimentos e produção de micotoxinas ${ }^{15}$. Esses fungos estão distribuídos em todo o mundo, uma vez que crescem em uma ampla faixa de temperatura (de $14{ }^{\circ} \mathrm{C}$ a $43{ }^{\circ} \mathrm{C}$ ), sendo mais frequentes em regiões de clima subtropical e temperado ${ }^{2,35,36}$.

A produção de aflatoxinas foi reportada em três diferentes grupos de Aspergilli: Aspergillus seção Flavi, Aspergillus seção Nidulantes e Aspergillus seção Ochraceorosei ${ }^{37}$. No Brasil, foram relatadas apenas três espécies produtoras de aflatoxinas pertencentes à seção Flavi (A. flavus, A. parasiticus e A. nomius). A espécie $A$. flavus encontra-se amplamente distribuída e é a principal produtora de aflatoxina tipo $B$, enquanto as outras duas espécies são mais frequentemente reportadas como produtoras de aflatoxinas tipo B e $\mathrm{G}$ em amostras naturalmente contaminadas ${ }^{38}$.

A imunofluorescência, o ELISA e o imunossensor são técnicas imunológicas utilizadas para detectar espécies toxigênicas de Aspergillus em alimentos 
visando avaliar o nível de contaminação. O ELISA é o principal método imunológico utilizado, e o imunossensor, que começou a ser desenvolvido mais recentemente, é um método promissor.

A imunofluorescência utilizando anticorpos de coelho contra antígeno micelial de A. flavus foi um dos primeiros métodos imunológicos desenvolvidos para detectar esse fungo em grãos ${ }^{39}$. Os grãos eram incubados com soro de coelho antiantígeno micelial de A. flavus, lavados e incubados com anticorpo anti-IgG de coelho marcado com fluoresceína e examinados por microscopia de fluorescência. Os anticorpos antiantígeno micelial de A. flavus apresentaram forte fluorescência quando incubados com micélio de $A$. flavus e $A$. candidus, fluorescência moderada com micélio de $A$. fumigatus e fluorescência tênue com micélios de espécies de outros gêneros fúngicos. Embora esse método possibilite a detecção de $A$. flavus em grãos, apresenta como restrição a necessidade de análise individual dos grãos, de modo que não é viável sua utilização na avaliação de contaminação de grandes quantidades de amostras.

O ensaio imunoenzimático utilizando microplacas permite a análise de diversas amostras simultaneamente e possibilita o monitoramento de grande número de amostras. Um ELISA sanduíche baseado em anticorpo de coelho para antígenos miceliais de $A$. parasiticus foi utilizado para detectar fungos aflatoxigênicos em cereais (milho, amendoim, arroz e trigo) natural e artificialmente contaminados. Essa técnica apresentou um limite de detecção para A. parasiticus de $1 \mu \mathrm{g} / \mathrm{mL}$ e uma forte correlação positiva com o método tradicional de contagem em placa a um nível de atividade de água $\left(a_{\mathrm{w}}\right)$ de 0,98, com coeficientes de correlação de $0,94,0,93,0,96$ e 0,86 para milho, arroz, trigo e amendoim, respectivamente. Em níveis de $a_{\mathrm{w}}$ mais baixos, essa correlação diminuiu, provavelmente devido ao fato de o ELISA quantificar o antígeno micelial e a contagem em placa detectar colônias provenientes tanto de esporos quanto de micélios, sendo a formação de esporos favorecida por $a_{\mathrm{w}}$ baixos. Em amostras naturalmente contaminadas, foi necessária a hidratação $\left(a_{\mathrm{w}}=0,92\right)$ e a incubação a $28{ }^{\circ} \mathrm{C}$ por 29 dias para que o ensaio imunoenzimático detectasse fungos aflatoxigênicos em $52 \%$ das amostras analisadas $^{40}$.

Yong e Cousin ${ }^{41}$ utilizaram um ELISA sanduíche ${ }^{42,43}$ para detectar $A$. parasiticus em amostras de milho naturalmente contaminadas por aflatoxinas e em amostras de amendoim e milho artificialmente contaminadas por esse fungo. Os anticorpos policlonais de coelho para antígenos extracelulares de $A$. parasiticus utilizados nesse teste apresentaram reatividade cruzada apenas com antígenos extracelulares e miceliais de três espécies (A. flavus, 
A. oryzae e A. sojae) das 37 analisadas. Todas as amostras de milho naturalmente contaminadas por aflatoxinas foram positivas no ELISA sanduíche e estavam contaminadas com fungos aflatoxigênicos, e duas amostras com contagem de fungos $\left(10^{3} \mathrm{CFU} / \mathrm{g}\right)$ foram positivas no ELISA apesar da ausência de aflatoxinas. A análise diária de milho e de amendoim contaminados artificialmente com A. parasiticus quanto aos níveis de antígeno e aflatoxinas demonstrou a capacidade do ELISA sanduíche de detectar antígeno antes que níveis detectáveis de aflatoxinas por cromatografia em camada delgada fossem produzidos, sugerindo que esse método apresenta potencial para detecção precoce de fungos produtores de aflatoxinas.

Anticorpos produzidos contra duas proteínas quiméricas recombinantes produzidas em Escherichia coli, resultantes dos genes ver-1 e apa-2 de A. parasiticus, que estão envolvidos na biossíntese de aflatoxinas, apresentaram potencial para serem utilizados em métodos imunológicos para detecção de fungos aflatoxigênicos. Esses anticorpos reagiram mais fortemente com antígeno de $A$. parasiticus e A. flavus em relação a antígenos de outros fungos quando analisados por ELISA, enquanto os anticorpos produzidos contra o filtrado do cultivo de A. parasiticus reagiram com todas as espécies de Aspergillus e Penicillium, indicando a maior especificidade dos anticorpos produzidos contra as proteínas quiméricas envolvidas na biossíntese de aflatoxinas ${ }^{44}$.

Villamizar, Maroto e Rius ${ }^{45}$ desenvolveram um biossensor eletroquímico para detecção de A. flavus de forma mais rápida que o ELISA. O dispositivo é constituído por um transistor de efeito de campo de nanotubos de carbono ligado a anticorpo de coelho anti-A. flavus. A ligação do antígeno fúngico ao anticorpo causa alterações na corrente elétrica que podem ser medidas em função da voltagem ${ }^{46}$. O biossensor desenvolvido nesse trabalho apresentou um limite de detecção de $10 \mu \mathrm{g} / \mathrm{g}$ para amostras de arroz artificialmente contaminadas por $A$. flavus e apresentou reatividade cruzada com P. chrysogenum a $100 \mathrm{ng} / \mathrm{mL}$. A aplicação do biossensor para detecção de espécies de Aspergillus produtoras de aflatoxinas em amostras de arroz é promissora, uma vez que não apresentou reatividade com $P$. chrysogenum em concentrações abaixo de $100 \mathrm{ng} / \mathrm{mL}$ e o resultado é obtido em apenas 30 minutos.

Outro biossensor para detecção de espécies de Aspergillus aflatoxigênicas baseado na imobilização de anticorpos de coelho antiantígeno extracelular de A. parasiticus sobre eletrodo de ouro modificado foi desenvolvido por Sun et al. ${ }^{47}$. O biossensor apresentou alta reatividade com antígenos de $A$. parasiticus e $A$. flavus $(88,0 \%$ a $98,2 \%)$ e baixa reatividade com 
outras espécies de Aspergillus e outros gêneros fúngicos (4\% a 16\%). A taxa de recuperação média de $A$. parasiticus inoculado em suspensão de soja variou de $81,5 \%$ a $113,5 \%$. O método também permitiu a detecção de A. parasiticus durante o processo de produção e fermentação da pasta de soja. As contagens de Aspergillus aflatoxigênicos foram maiores durante o processo de produção e diminuíram gradualmente durante o período de fermentação. Por outro lado, os níveis de $\mathrm{AFB}_{1}$ foram maiores com dois meses de fermentação e diminuíram gradualmente, sugerindo que esse imunossensor possibilita a detecção precoce de aflatoxinas durante o processamento de alimentos.

\subsubsection{Fusarium spp.}

As espécies de Fusarium são importantes fitopatógenos, causando uma ampla variedade de doenças tais como apodrecimento de raiz e caule, que causam prejuízos econômicos a agricultores por afetar a produtividade e a qualidade de produtos agrícolas. Além disso, produzem diversas micotoxinas, como fumonisinas, zearalenona, tricotecenos, desoxinivalenol e toxina T-2, que afetam a saúde de seres humanos e animais ${ }^{15}$.

As fumonisinas são produzidas principalmente por F. verticillioides Nirenberg (= Fusarium moniliforme Sheldon) e F. proliferatum (Matsushima) Nirenberg ${ }^{48}$ e estão associadas a diversas doenças em animais e seres humanos ${ }^{5,49-51}$.

O ELISA é o principal método imunológico desenvolvido para detectar espécies de Fusarium e é utilizado no monitoramento da eficiência de fungicidas, na determinação da resistência de linhagens de plantas e no controle de qualidade de grãos ${ }^{52-58}$.

A detecção é baseada na interação de anticorpos específicos com antígenos do fungo, como componentes miceliais e exoantígenos ${ }^{59-61}$. Exoantígenos são macromoléculas imunogênicas produzidas e secretadas por fungos no meio de cultura que podem ser utilizados na detecção e identificação de fungos por serem espécie ou gênero-específicos para muitas espécies fúngicas ${ }^{60}$.

O ELISA pode detectar a presença de fungos em alimentos processados por tratamento térmico, filtração e irradiação gama, e pode detectar quantitativamente a biomassa fúngica ${ }^{62}$.

Gan et al. ${ }^{59}$ caracterizaram anticorpos produzidos em galinhas contra antígenos miceliais solúveis e exoantígenos de três espécies toxigênicas de Fusarium (F. graminearum, F. poae e F. sporotrichioides). Os anticorpos 
produzidos contra os antígenos miceliais solúveis apresentaram reatividade cruzada com antígenos de outros gêneros fúngicos, enquanto os anticorpos produzidos contra os exoantígenos de F. graminearum e F. sporotrichioides apresentaram especificidade quanto ao gênero, enquanto que os anticorpos produzidos contra os exoantígenos de $F$. poae apresentaram especificidade quanto à espécie. Os anticorpos não apresentaram reatividade cruzada com extrato de grãos, sugerindo sua aplicabilidade na detecção de Fusarium spp. em cereais.

Baseando-se no trabalho de Gan et al. ${ }^{59}$, Abramson et al. ${ }^{63}$ desenvolveram um ic-ELISA utilizando anticorpos produzidos em galinhas contra exoantígeno de F. sporotrichioides para detectar exoantígeno de Fusarium spp. em amostras de trigo natural e artificialmente contaminadas. Esse anticorpo foi selecionado por ser gênero-específico e pela capacidade de reagir com exoantígenos de outras espécies de Fusarium, incluindo as cinco espécies toxigênicas mais importantes (F. graminearum, F. poae, F. sporotrichioides, F. equiseti e F. verticillioides $)^{59,64,65}$. O ELISA desenvolvido nesse estudo apresentou potencial para ser utilizado na detecção de exoantígenos de Fusarium spp. em amostras de trigo, apresentando um limite de detecção de 0,03 $\mu \mathrm{g} /$ $\mathrm{mL}$. As concentrações de exoantígenos de Fusarium spp. determinadas por esse método variaram de 1,76 $\mu \mathrm{g} / \mathrm{g}$ a $52,80 \mu \mathrm{g} / \mathrm{g}$ com valor médio de 13,00 $\mu \mathrm{g} / \mathrm{g}$ em amostras de trigo artificialmente contaminadas e de $1,23 \mu \mathrm{g} / \mathrm{g}$ a $15,52 \mu \mathrm{g} / \mathrm{g}$ com valor médio de 4,16 $\mu \mathrm{g} / \mathrm{g}$ em amostras de trigo naturalmente contaminadas. Essas concentrações de exoantígenos apresentaram uma forte correlação positiva com os níveis de desoxinivalenol (DON) determinados por espectrometria de massa e ELISA, com coeficientes de correlação de 0,8 para amostras de trigo artificialmente contaminadas e de 0,76 para amostras de trigo naturalmente contaminadas.

Outro ic-ELISA gênero-específico para detecção de Fusarium spp. em alimentos e grãos foi desenvolvido por Iyer e Cousin ${ }^{66}$, utilizando anticorpos de coelho contra proteínas extraídas do micélio de F. graminearum e $F$. verticillioides, apresentando um limite de detecção para F. graminearum e $F$. verticillioides de $0,1 \mu \mathrm{g} / \mathrm{mL}$ e $1,0 \mu \mathrm{g} / \mathrm{mL}$, respectivamente.

Meirelles et al. ${ }^{54}$ desenvolveram um ic-ELISA utilizando anticorpos de coelho contra exoantígenos de F. verticillioides com o objetivo de quantificar exoantígenos de F. verticillioides em amostras de milho recém-colhido. O limite de detecção desse ensaio foi de $1,6 \mu \mathrm{g} / \mathrm{g}$, e as concentrações de exoantígenos determinadas por esse método variaram de 8,9 $\mu \mathrm{g} / \mathrm{g}$ a 965,0 $\mu \mathrm{g} / \mathrm{g}$, com valor médio de $217,3 \mu \mathrm{g} / \mathrm{g}$. Essas concentrações apresentaram alta correlação positiva $(0,84)$ com a biomassa de F. verticillioides cultivado em 
caldo de infusão de cérebro e coração, correlação positiva média com os níveis de ergosterol $(0,52)$ e não apresentaram correlação com os níveis de fumonisinas $(0,05)$. A falta de correlação entre as concentrações de exoantígenos e de fumonisinas pode dever-se à falta de especificidade do método ao exoantígeno de F. verticillioides, uma espécie produtora de fumonisinas, uma vez que os anticorpos policlonais de coelho contra exoantígenos de $F$. verticillioides apresentaram alta reatividade cruzada com exoantígenos de F. graminearum (51\%), F. subglutinans $(76 \%)$ e F. sporotrichioides $(65 \%)^{67}$. Portanto, esse método foi gênero-específico e permitiu a detecção e quantificação de exoantígenos de Fusarium spp. em amostras de milho.

A utilização de anticorpo monoclonal específico para Fusarium spp. no desenvolvimento de ELISA indireto para detectar espécies de Fusarium causadoras de giberela em grãos de cevada infectados artificial ou naturalmente foi relatado por Hill et al. ${ }^{53}$. Esse ELISA indireto permitiu a quantificação de antígenos extraídos dos grãos e apresentou um coeficiente de correlação de 0,51 e 0,71 com níveis de DON em grãos de cevada contaminados artificial e naturalmente, respectivamente. O método também detectou Fusarium spp. em grãos sem sinais de infecção, indicando sua maior precisão em comparação ao método de análise visual de giberela em plantas.

Hill et al. ${ }^{68}$ compararam a eficiência do ELISA indireto ${ }^{53} \mathrm{com}$ a triagem visual e a análise de DON na avaliação da gravidade de giberela em amostras de cevada de diferentes localizações com diferentes condições ambientais. Os autores sugeriram que a quantificação de Fusarium spp. por ELISA é uma técnica precisa para avaliar a contaminação fúngica de cevada e apresenta menor coeficiente de variação quando comparado à análise de DON e do score de giberela.

$\mathrm{Na}$ tentativa de desenvolver um método específico para detecção de espécies de Fusarium potencialmente produtoras de fumonisinas, Grimm e Geisen ${ }^{69}$ desenvolveram um PCR-ELISA, que apresentou maior especificidade quando comparado com os resultados da PCR, detectando todas as espécies potencialmente produtoras de fumonisinas estudadas e não apresentando reação com as espécies não produtoras de fumonisinas. Esse método consiste basicamente em realizar os procedimentos de um ELISA para detecção do produto de uma PCR. Os produtos da PCR são marcados com digoxigenina e incubados com sondas oligonucleotídicas marcadas com biotina que apresentam sequência complementar à sequência-alvo. Assim, caso os produtos da PCR apresentem essa sequência-alvo, ocorrerá a ligação específica desses produtos da PCR marcados com digoxigenina às sondas oligonucleotídicas marcadas com biotina. Esse híbrido é então capturado pela 
estreptavidina presente nos poços da microplaca através da biotina, e os produtos não específicos da PCR, que não se ligam à sonda, são removidos por lavagens. Em seguida, o híbrido é incubado com conjugado antidigoxigenina-peroxidase, ocorrendo a ligação do conjugado com a digoxigenina presente nos produtos da PCR. Por fim, é adicionado um substrato que ao reagir com o conjugado enzimático resulta em um produto colorido que é analisado por espectrofotometria ${ }^{70,71}$.

\subsection{IMUNOENSAIOS PARA DETECC̣ÃO DE MICOTOXINAS}

\subsubsection{Aflatoxinas}

As aflatoxinas foram descobertas em 1960, após a morte de aproximadamente 100 mil perus na Inglaterra (Turkey $X$ disease) que consumiram ração contendo torta de amendoim contaminada proveniente do Brasil ${ }^{72,73}$.

Estruturalmente, as aflatoxinas são bisfuranos ligados a um anel cumarínico central, sendo conhecidos ao menos 20 análogos, dos quais os principais são aflatoxina $\mathrm{B}_{1}\left(\mathrm{AFB}_{1}\right), \mathrm{AFB}_{2}, \mathrm{AFG}_{1}$ e $\mathrm{AFG}_{2}{ }^{74,75}$. $\mathrm{A} \mathrm{AFB}_{1}$ é o análogo mais frequente e mais tóxico, seguido por $\mathrm{AFG}_{1}, \mathrm{AFB}_{2}$ e $\mathrm{AFG}_{2}$, que exibem toxicidade de $50 \%, 20 \%$ e $10 \%$ em relação à $\mathrm{AFB}_{1}$, respectivamente ${ }^{76}$. As $\mathrm{AFB}_{1}$ e $\mathrm{AFG}_{1}$ contêm um anel diidrofurano, e as $\mathrm{AFB}_{2}$ e $\mathrm{AFG}_{2}$ contêm um tetradiidrofurano ${ }^{3,75}$.

Os produtos agrícolas com maior risco de contaminação por aflatoxinas são amendoim, milho, castanha-do-pará, pistache, pimenta e figo ${ }^{3}$. A aflatoxina $\mathrm{M}_{1}\left(\mathrm{AFM}_{1}\right)$, que é um produto da metabolização da $\mathrm{AFB}_{1}$ dos organismos de animais lactentes, é a forma mais frequente em leite e derivados ${ }^{77}$.

Os efeitos tóxicos e carcinogênicos da $\mathrm{AFB}_{1}$ são atribuídos aos derivados hidroxilados de metabolização pela monoxigenase citocromo P-450-dependente (CYP) nos hepatócitos. Essa enzima catalisa o metabolismo oxidativo da $\mathrm{AFB}_{1}$, resultando na formação de vários derivados hidroxilados como a $\mathrm{AFM}_{1}$ (mais frequente), $\mathrm{AFQ}_{1}$ e $\mathrm{AFP}_{1}$ (menor toxicidade), bem como a formação do $\mathrm{AFB}_{1}-8,9$-epóxido $(\mathrm{AFBO})$, que é altamente reativo. A interação dos metabólitos da $\mathrm{AFB}_{1}$ com DNA promove a formação principalmente de aduto macromolecular $\mathrm{AFB}_{1}-\mathrm{N}^{7}$-guanina (8,9-dihidro-8-( $\mathrm{N}^{7}$-guanil)-9-dihidroxiaflatoxina $\left.\mathrm{B}_{1}\right)^{78-81}$, que pode causar uma mutação somática pontual no gene TP53 (transversão GC para TA na terceira base do códon 249) resultando em mutação na proteína p53, que é considerada a alteração genética 
mais comum associada ao câncer em seres humanos ${ }^{82-86}$. Adicionalmente, a $\mathrm{AFB}_{1}$ pode induzir a formação de espécies reativas de oxigênio (ROS), as quais promovem a oxidação do $\mathrm{DNA}^{87}$.

A intoxicação provocada pela ingestão de aflatoxinas, denominada aflatoxicose, pode ocorrer de forma aguda ou crônica em seres humanos e animais. A aflatoxicose aguda em seres humanos é caracterizada por febre alta, vômito, colúria, edema dos pés, icterícia, desenvolvimento de ascite, hipertensão portal e apresenta uma alta taxa de mortalidade ${ }^{88,89}$. Além disso, duas doenças humanas de etiologia indefinida têm sido associadas ao consumo de alimentos contaminados com aflatoxinas: Kwashiorkor e síndrome de Reye ${ }^{90-92}$. Por outro lado, a exposição crônica está associada ao câncer hepático e pulmonar ${ }^{93-95}$, alterações na resposta imunológica ${ }^{96}$ e diminuição na concentração de selênio plasmático ${ }^{97}$.

Os efeitos tóxicos das aflatoxinas em animais incluem redução do peso corporal e alterações na atividade de macrófagos em aves ${ }^{98,99}$; redução do ganho de peso em suínos ${ }^{100}$; hepatite, anorexia, coagulação intravascular disseminada, letargia e icterícia em cães e gatos ${ }^{101}$; carcinoma hepatocelular em $\operatorname{ratos}^{102}$; redução do ganho de peso e redução na produção de leite em bovinos ${ }^{103,104}$; lesão hepática e renal, alteração no metabolismo mineral e redução no ganho de peso em caprinos ${ }^{105,106}$.

As aflatoxinas são classificadas pela Agência Internacional para Pesquisa sobre o Câncer (IARC) como carcinógenos do grupo 1(carcinogênico para seres humanos $)^{107}$. A $A_{1 F B}$ é considerada o mais potente carcinógeno natural conhecido e, geralmente, o análogo mais produzido pelas cepas toxigênicas ${ }^{108,109}$.

A Comissão Europeia estabeleceu limites máximos tolerados de 20,0 $\mu \mathrm{g} /$ $\mathrm{Kg}$ para aflatoxina $\mathrm{B}_{1}$ em ração animal, com exceção de bovinos leiteiros e bezerros, ovelhas leiteiras e cordeiros, cabras e cabritos, leitões e aves $(5,0$ $\mu \mathrm{g} / \mathrm{Kg})^{110}$.

Não existe uma legislação para os limites máximos tolerados de aflatoxinas em ração animal no Brasil. No entanto o Grupo de Trabalho sobre Micotoxinas do Ministério da Agricultura recomendou um limite máximo de $20,0 \mu \mathrm{g} / \mathrm{Kg}$ para aflatoxinas totais em milho em grão e em subprodutos destinados à alimentação animal ${ }^{111}$. O limite máximo recomendado para a aflatoxina $B_{1}$ em ração destinada a ruminantes é de $50,0 \mu \mathrm{g} / \mathrm{Kg}$; para animais das demais espécies, incluindo ruminantes lactentes, de $20,0 \mu \mathrm{g} / \mathrm{Kg}$, e para todas as espécies animais nas fases pré-inicial e inicial é de $10,0 \mu \mathrm{g} / \mathrm{Kg}$ (Tabela 24.1). 
Em relação à alimentação humana, os limites máximos tolerados em diversos alimentos foram estabelecidos para aflatoxinas totais e aflatoxina $\mathrm{B}_{1}$, separadamente. Em amendoim, avelã e castanha-do-pará o limite máximo tolerado para aflatoxinas totais e aflatoxina $\mathrm{B}_{1}$ é de $15,0 \mu \mathrm{g} / \mathrm{Kg}$ e $8,0 \mu \mathrm{g} / \mathrm{Kg}$, respectivamente; em cereais é de 4,0 e 2,0 $\mu \mathrm{g} / \mathrm{Kg}$, respectivamente; em milho e arroz, de 5,0 e 1,0 $\mu \mathrm{g} / \mathrm{Kg}$, respectivamente ${ }^{112}$.

No Brasil, os limites máximos tolerados para aflatoxinas totais $\left(\mathrm{AFB}_{1}+\mathrm{AFB}_{2}+\mathrm{AFG}_{1}+\mathrm{AFG}_{2}\right)$ foram estabelecidos para diversos alimentos destinados ao consumo humano ${ }^{14}$. Em cereais, este limite é de $5,0 \mu \mathrm{g} / \mathrm{Kg}$; em castanha-do-pará varia de $10,0 \mu \mathrm{g} / \mathrm{Kg}$ a $20,0 \mu \mathrm{g} / \mathrm{Kg}$; e em amendoim e em milho, incluindo farinha e semolina, é de 20,0 $\mathrm{gg} / \mathrm{Kg}$ (Tabela 24.1).

Tabela 24.1 Limites máximos tolerados (LTM) para aflatoxinas em alimentos e rações. Fonte: Brasil (2006) ${ }^{111}$ e Brasil $(2011)^{14}$

\begin{tabular}{|c|c|c|}
\hline MICOTOXINA & ALIMENTOS & LMT $(\mu g / K g)$ \\
\hline \multirow{12}{*}{$\begin{array}{l}\text { Aflatoxinas } \\
B_{1}, B_{2}, G_{1}, G_{2}\end{array}$} & Cereais e produtos de cereais, exceto milho e derivados, incluindo cevada malteada & 5 \\
\hline & Feiija & 5 \\
\hline & Castanhas exceto castanha-do-brasil, incluindo nozes, pistaches, avelãs e amêndoas & 10 \\
\hline & Frutas desidratadas e secas & 10 \\
\hline & Castanha-do-brasil com casca para consumo direto & 20 \\
\hline & Castanha-do-brasil sem casca para consumo direto & 10 \\
\hline & Castanha-do-brasil sem casca para processamento posterior & 15 \\
\hline & Alimentos à base de cereais para alimentação infantil & 1 \\
\hline & Amêndoas de cacau & 10 \\
\hline & Produtos de cacau e chocolate & 5 \\
\hline & $\begin{array}{l}\text { Amendoim (com casca, descascado, cru ou tostado), } \\
\text { pasta de amendoim ou manteiga de amendoim }\end{array}$ & 20 \\
\hline & $\begin{array}{l}\text { Milho, milho em grãos (inteiro, partido, amassado, } \\
\text { moído), farinhas ou sêmolas de milho }\end{array}$ & 20 \\
\hline \multicolumn{3}{|c|}{ RAC̦ÕES } \\
\hline \multirow{3}{*}{ Aflatoxina $B_{1}$} & Rações e concentrados para ruminantes adultos, exceto bovinos em lactação & 50 \\
\hline & Rações e concentrados para demais espécies, incluindo bovinos em lactaçã̃o & 20 \\
\hline & $\begin{array}{l}\text { Rações, concentrados e outros alimentos completos para animais } \\
\text { de todas as espécies nas fases pré-inicial e inicial }\end{array}$ & 10 \\
\hline
\end{tabular}

Diversos métodos imunológicos podem ser utilizados para detecção de aflatoxinas, incluindo o ELISA ${ }^{17,113-121}$, imunocromatografia ${ }^{118,121-126}$, dipstick $^{30,127}$ e biossensores ${ }^{128-134}$. 
Asis et al. ${ }^{113}$ desenvolveram um ic-ELISA para quantificação de aflatoxina $\mathrm{B}_{1}$ em extrato de amendoim e pasta de amendoim. As amostras foram previamente contaminadas com Aspergillus spp. e analisadas por CLAE e por ic-ELISA. O coeficiente de correlação entre os dois métodos foi de 0,977 , o limite de detecção de $0,5 \mu \mathrm{g} / \mathrm{Kg}$ e a taxa de recuperação de $107 \%$.

Lipigorngoson et al. ${ }^{117}$ desenvolveram um dc-ELISA baseado em anticorpo monoclonal para detecção de aflatoxina $\mathrm{B}_{1}$ em milho e amendoim. O limite de detecção foi de $4,0 \mu \mathrm{g} / \mathrm{Kg}$, com taxa de recuperação de $88,1 \%$ e 99,5\%. A comparação do dc-ELISA com kits comerciais de ELISA e com a cromatografia em camada delgada (CCD) apresentou um bom coeficiente de correlação, que foi de 0,912 e 0,802 , respectivamente, para o milho, e de 0,941 e 0,832 , respectivamente, para o amendoim.

Guan et al. ${ }^{115}$ desenvolveram um ic-ELISA baseado em anticorpo monoclonal sensível e específico para detectar $\mathrm{AFM}_{1}$ em amostras de leite e produtos lácteos infantis. $\mathrm{O}$ anticorpo não apresentou reatividade cruzada contra a $\mathrm{AFB}_{1}, \mathrm{AFB}_{2}, \mathrm{AFG}_{1}$ e $\mathrm{AFG}_{2}$, e o limite de detecção foi de $3 \mathrm{ng} / \mathrm{L}$ e 6 ng/L para o leite e produtos lácteos, respectivamente. A taxa de recuperação variou entre $91 \%$ e $110 \%$. O ensaio apresentou uma alta correlação $(0,98)$ quando comparado com a CLAE.

Um ic-ELISA baseado em anticorpo monoclonal contra $A_{F} B_{1}$ foi padronizado e validado para a detecção de aflatoxinas em ração de aves e comparado com a CLAE. O ic-ELISA mostrou uma boa linearidade $(0,994)$ e um limite de detecção de $1,25 \mathrm{ng} / \mathrm{g}$ em ração de frangos de corte e de 1,41 ng/g em ração de galinhas poedeiras. A taxa de recuperação de $\mathrm{AFB}_{1}$ foi $98 \%$ e $102 \%$ para a ração de frangos de corte e de galinhas poedeiras, respectivamente. O ic-ELISA apresentou uma boa correlação com a CLAE para ração de frangos de corte $(0,97)$ e para ração de galinhas poedeiras $(0,98)$ indicando ser um método eficiente para a triagem de aflatoxinas em rações de aves ${ }^{120}$.

Liu et al. ${ }^{118}$ desenvolveram um dc-ELISA e uma imunocromatografia utilizando anticorpo marcado com ouro coloidal para a detecção de $\mathrm{AFB}_{1} \mathrm{em}$ café, arroz-vermelho (red yeast rice) e ração à base de milho. Os limites de detecção do dc-ELISA e da imunocromatografia foram de $0,02 \mathrm{ng} / \mathrm{mL}$ e 2,00 $\mathrm{ng} / \mathrm{mL}$, respectivamente. A imunocromatografia permitiu distinguir as amostras contaminadas com concentrações acima de 72,40 ng/g de $\mathrm{AFB}_{1}$.

Zhang et al. ${ }^{126}$ desenvolveram uma imunocromatografia baseada em um ensaio competitivo utilizando anticorpo monoclonal marcado com ouro coloidal, para a detecção qualitativa de aflatoxinas totais $\left(\mathrm{AFB}_{1}, \mathrm{AFB}_{2}, \mathrm{AFG}_{1}\right.$ e $\mathrm{AFG}_{2}$ ) em amendoim. Os limites de detecção foram de $0,03 \mathrm{ng} / \mathrm{mL}, 0,06$ 
$\mathrm{ng} / \mathrm{mL}, 0,12 \mathrm{ng} / \mathrm{mL}$ e $0,25 \mathrm{ng} / \mathrm{mL}_{\text {para }} \mathrm{AFB}_{1}, \mathrm{AFB}_{2}, \mathrm{AFG}_{1}$ e $\mathrm{AFG}_{2}$, respectivamente. $\mathrm{O}$ método apresentou alta sensibilidade, rapidez e baixo custo para a detecção qualitativa de aflatoxinas em amendoim.

Uma imunocromatografia utilizando anticorpo monoclonal conjugado a ouro coloidal e imobilizado em membrana de nitrocelulose foi desenvolvida para a detecção qualitativa de $\mathrm{AFB}_{1}$ em ração para suínos, com um limite de detecção de 5,0 $\mu \mathrm{g} / \mathrm{Kg}$. A extração da amostra foi realizada utilizando uma mistura de metanol:água $(80: 20 \mathrm{v} / \mathrm{v})$, e a tira de nitrocelulose foi imersa nesse extrato por 10 minutos, sendo que o conjugado se dissolveu e permaneceu no extrato. Em amostras positivas, $\mathrm{AFB}_{1}$ presente na amostra foi capaz de se ligar ao conjugado. Porém, em amostras negativas, o conjugado permaneceu livre e fluiu ao longo da membrana. Ao atingir a linha teste, o conjugado livre se ligou à $\mathrm{AFB}_{1}$ imobilizada, formando uma linha colorida. A linha controle presente na membrana assegura que o conjugado fluiu ao longo da membrana e garante a validade do teste. Portanto, a presença de duas linhas coloridas (linha teste e controle) indica que a amostra contém uma concentração de $\mathrm{AFB}_{1}$ menor que $5,0 \mu \mathrm{g} / \mathrm{Kg}$. Por outro lado, a aparição de somente uma linha (linha controle) indica que a amostra está contaminada com concentrações acima de $5,0 \mu \mathrm{g} / \mathrm{Kg}$. O método desenvolvido foi capaz de discriminar amostras positivas e negativas, indicando seu potencial para a triagem in situ $u^{30}$.

Um imunossensor baseado em um imunoensaio competitivo indireto foi desenvolvido para a detecção de $\mathrm{AFB}_{1}$ em cevada, utilizando um detector eletroquímico (screen printed electrode). O limite de detecção foi de 2,0 ng $\mathrm{AFB}_{1} / \mathrm{g}$ de cevada, e a taxa de recuperação variou de $93 \%$ a $117 \%$ (média de $105 \% \pm 8 \%$ ) tanto para o ELISA espectrofotométrico quanto para o eletroquímico ${ }^{128}$.

Um imunossensor desenvolvido pelo Naval Research Laboratory (NLR biosensor array) baseado em imunoensaio competitivo indireto foi utilizado para a detecção de $\mathrm{AFB}_{1}$ em derivados de milho e em amendoim, nozes e manteiga de amendoim. A intensidade da fluorescência diminuiu com o aumento da concentração de $\mathrm{AFB}_{1}$. O limite de detecção para amostras de pipoca, flocos de milho e farinha de milho variou de $1,5 \mathrm{ng} / \mathrm{g}$ a $5,1 \mathrm{ng} / \mathrm{g}$, e, para amostras de amendoim, nozes e manteiga de amendoim, variou de 0,6 $\mathrm{ng} / \mathrm{g}$ a $1,4 \mathrm{ng} / \mathrm{g}^{132}$.

Um imunossensor eletroquímico baseado na amplificação enzimática por deposição de prata foi desenvolvido para a detecção de $\mathrm{AFB}_{1}$ em arroz. $\mathrm{O}$ imunossensor foi baseado em um imunoensaio competitivo indireto entre a $\mathrm{AFB}_{1}$ livre e o conjugado $\mathrm{AFB}_{1}$-soroalbumina bovina $\left(\mathrm{AFB}_{1}-\mathrm{BSA}\right)$ imobilizado 
na superfície do eletrodo para a ligação do anticorpo anti-AFB . $_{1} \mathrm{O}$ anticorpo anti-IgG marcado com fosfatase alcalina foi ligado à superfície do eletrodo por meio da ligação com o anticorpo anti-AFB ${ }_{1}$ para converter o substrato, 2 -fosfato de ácido ascórbico, em ácido ascórbico que reduz os íons prata em solução a metal de prata depositado na superfície do eletrodo. A voltametria de varredura linear foi utilizada para quantificar a prata depositada, a qual refletiu indiretamente a concentração do analito. O limite de detecção foi de $0,06 \mathrm{ng} / \mathrm{mL}$, e a taxa de recuperação em amostras de arroz variou de 88,5\% a $112 \%{ }^{134}$.

Um imunossensor, utilizando um screen-printed electrode, foi desenvolvido para a detecção de $\mathrm{AFM}_{1}$ em leite. O método foi baseado na competição entre a $\mathrm{AFM}_{1}$ presente nas amostras e o conjugado $\mathrm{AFM}_{1}$-peroxidase

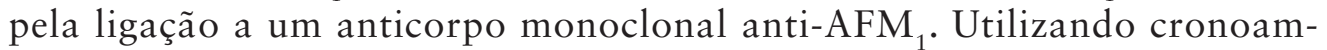
periometria, o sinal gerado pelo uso de TMB (3,3', 5,5' tetrametilbenzidina) $/ \mathrm{H}_{2} \mathrm{O}_{2}$ foi monitorado para determinar a concentração de peroxidase e, consequentemente, a concentração de $\mathrm{AFM}_{1}$ na amostra. Nesse método ocorreu um efeito de matriz devido à presença de proteínas de soro do leite. Após tratamento com cloreto de cálcio $(18 \mathrm{mM})$, o problema foi eliminado e foi obtido um limite de detecção de 39 ng AFM $/$ L. Comparado com os kits comerciais de ELISA, o imunossensor apresentou um limite de detecção similar e comparável repetitividade. A CLAE apresentou maior sensibilidade que o imunossensor, com limite de detecção de $10 \mathrm{ng} / \mathrm{L}$. Esse método, porém, requer a utilização de colunas de imunoafinidade, aumentado os custos do método e tornando-o mais complexo ${ }^{135}$.

\subsubsection{Fumonisinas}

Estruturalmente, as fumonisinas consistem em uma cadeia linear com 19 ou 20 carbonos ramificados com grupos hidroxil, metil e ácidos tricarboxílicos em várias posições ao longo da cadeia ${ }^{136}$. Ao menos 28 análogos de fumonisinas foram caracterizados e divididos em quatro grupos principais, identificados como fumonisinas das séries A, B, C e $\mathrm{P}^{137}$. Os análogos da série $\mathrm{B}$, incluindo as fumonisinas $\mathrm{B}_{1}\left(\mathrm{FB}_{1}\right), \mathrm{B}_{2}\left(\mathrm{FB}_{2}\right)$ e $\mathrm{B}_{3}\left(\mathrm{FB}_{3}\right)$, são as mais tóxicas e abundantes em milho e derivados, sendo que a $\mathrm{FB}_{1}$ é a mais frequente e detectada em maiores concentrações ${ }^{138}$.

$\mathrm{A} \mathrm{FB}_{1}$ é um diéster de propano-1,2,3-ácido tricarboxílico e um 2-amino-12,16-dimetil, 3,5,10,14,15-penta-hidroxieicosano com grupos hidroxil esterificados com o grupo carboxiterminal dos ácidos em C-14 e C-15 136,139. 
A atividade tóxica das fumonisinas está relacionada à similaridade da sua estrutura com as bases esfingoides (esfingosina e esfinganina) ${ }^{140-142}$.

Devido a essa similaridade, as fumonisinas inibem competitivamente a ceramida sintase, principal enzima envolvida no metabolismo dos esfingolipídios e, consequentemente, causam o bloqueio da biossíntese da ceramida, aumento de esfinganina e, em menor proporção, de esfingosina, redução da reacilação das esfingosinas derivadas do turnover dos esfingolipídios, além da redução da degradação dos esfingolipídios da dieta ${ }^{143-146}$. Essas alterações estão associadas aos principais efeitos tóxicos das fumonisinas, que incluem a leucoencefalomalácia em equinos ${ }^{147}$, edema pulmonar em suínos ${ }^{148}$, efeitos hepatotóxico e hepatocarcinogênico em $\operatorname{ratos}^{149}$, efeitos nefrocarcinogênicos em $\operatorname{ratos}^{150}$ e redução do desenvolvimento em aves ${ }^{151}$. Além disso, estudos epidemiológicos com seres humanos indicam a associação das fumonisinas com o câncer esofágico na região de Transkei, África do Sul e China, câncer hepático primário ${ }^{50,152,153}$ e defeitos no tubo neural na Guatemala e no México ${ }^{154-156 .}$

A Agência Internacional para Pesquisa sobre o Câncer (IARC) classificou as fumonisinas como carcinógenos do grupo $2 \mathrm{~B}$ (possivelmente carcinogênicos para seres humanos) ${ }^{107}$.

Diversos países estabeleceram limites máximos tolerados para fumonisinas em alimentos e rações. A União Europeia recomendou um limite máximo tolerado de fumonisinas $\left(\mathrm{FB}_{1}+\mathrm{FB}_{2}\right)$ em milho e produtos derivados de milho destinados à alimentação animal de $60.000 \mu \mathrm{g} / \mathrm{Kg}^{157}$. Para a alimentação humana, o limite tolerado para fumonisinas em milho não processado e alimentos à base de milho é de $1.000 \mu \mathrm{g} / \mathrm{Kg}$, enquanto em cereais matinais e em alimentos infantis à base de milho é de $800 \mu \mathrm{g} / \mathrm{Kg}$ e $200 \mu \mathrm{g} / \mathrm{Kg}$, respectivamente ${ }^{158}$.

No Brasil, a Agência Nacional de Vigilância Sanitária (ANVISA) estabeleceu um limite para fumonisinas de $2.500 \mu \mathrm{g} / \mathrm{Kg}$, em 2012, para vários produtos derivados de milho (farinha de milho, creme de milho, flocos, fubá, canjica e canjiquinha) e de $2.000 \mu \mathrm{g} / \mathrm{Kg}$ para o amido e outros produtos à base de milho destinados ao consumo humano. Em 2017, os produtores de alimentos deverão se adequar à redução desses limites tolerados para fumonisinas, que deverá ser de $1.500 \mu \mathrm{g} / \mathrm{Kg}$ e $1.000 \mu \mathrm{g} / \mathrm{Kg}$, respectivamente. Em 2014, o limite máximo tolerado para milho em grãos foi estabelecido em $5.000 \mu \mathrm{g} / \mathrm{Kg}^{14}$ (Tabela 24.2). 
Tabela 24.2 Limites máximos tolerados (LTM) para fumonisinas em alimentos e rações. Fonte: Brasil $(2006)^{111}$ e Brasil $(2011)^{14}$

\begin{tabular}{|c|c|c|}
\hline MICOTOXINA & ALIMENTOS & LMT $(\mu g / K g)$ \\
\hline \multirow{8}{*}{$\begin{array}{l}\text { Fumonisinas } \\
\qquad\left(B_{1}+B_{2}\right)\end{array}$} & Milho de pipoca & 2.000 \\
\hline & Alimentos à base de milho para alimentação infantil & 200 \\
\hline & Farinha de milho, creme de milho, fubá, flocos, caniica, canjiquinha & 2.500 \\
\hline & Amido de milho e outros produtos à base de milho & 2.000 \\
\hline & Milho em grãos para posterior processamento & 5.000 \\
\hline & \multicolumn{2}{|l|}{ RAÇ̃̃ES } \\
\hline & Rações e concentrados para monogástricos, exceto aves domésticas & 5.000 \\
\hline & Rações e concentrados para aves domésticas & 10.000 \\
\hline
\end{tabular}

Não há uma legislação sobre os limites máximos tolerados de fumonisinas em ração animal no Brasil. No entanto, em 2006, foi criado o Grupo de Trabalho sobre Micotoxinas pelo Ministério da Agricultura que recomendou um limite máximo tolerado de fumonisinas em milho e trigo em grãos ou seus subprodutos destinados à alimentação animal de $10.000 \mu \mathrm{g} / \mathrm{Kg}^{111}$. O limite máximo recomendado para ração animal destinada a animais monogástricos é de $5.000 \mu \mathrm{g} / \mathrm{Kg}$ (Tabela 24.2).

Diversos métodos imunológicos, tais como ELISA, imunossensores, dipstick e imunocromatografia, têm sido desenvolvidos para a detecção de fumonisinas, especialmente para a triagem da contaminação de matérias-primas. Anticorpos monoclonais e policlonais têm sido utilizados para o desenvolvimento de dc-ELISA e ic-ELISA para a detecção de fumonisinas 22,159-162.

Sydenham et al. ${ }^{162}$ avaliaram a contaminação por fumonisinas em milho utilizando um dc-ELISA comercial baseado em anticorpo monoclonal (Agri Screen dc-ELISA). Apesar da superestimação da contaminação natural do milho em $50 \%$, uma alta correlação $(0,996)$ entre dc-ELISA e CLAE foi obtida utilizando milho artificialmente contaminado com fumonisinas com concentração variando de $0,8 \mu \mathrm{g} / \mathrm{g}$ a $12,8 \mu \mathrm{g} / \mathrm{g}$.

Yeung et al. ${ }^{163}$ desenvolveram um ic-ELISA baseado em anticorpo policlonal para a detecção de fumonisinas em milho. A reatividade cruzada ocorreu para $\mathrm{FB}_{1}(100 \%), \mathrm{FB}_{2}(55 \%), \mathrm{FB}_{3}(13 \%)$ e para os hidrolisados de fumonisinas $\mathrm{HFB}_{1}(11 \%)$ e $\mathrm{HFB}_{2}(3 \%)$. Contudo, não houve reatividade cruzada com outras micotoxinas. O limite de detecção em milho foi de $5,0 \mathrm{ng} / \mathrm{mL}$, e 
a concentração de fumonisinas detectada em milho naturalmente contaminado variou de $10,0 \mathrm{ng} / \mathrm{g}$ a $500,0 \mathrm{ng} / \mathrm{g}$.

Ono et al. ${ }^{22}$ desenvolveram um ic-ELISA baseado em anticorpo monoclonal para a detecção de fumonisinas em amostras de milho. O coeficiente de correlação entre a CLAE e o ELISA foi de 0,94, com um limite de detecção de 93,0 ng/g, indicando que é um método eficaz para a triagem da contaminação de milho por fumonisinas.

Um dc-ELISA baseado em anticorpo mococlonal foi desenvolvido para a detecção de $\mathrm{FB}_{1}$ em cereais. O limite de detecção foi de $7,6 \mathrm{ng} / \mathrm{mL}$ e as reatividades cruzadas para a $\mathrm{FB}_{1}, \mathrm{FB}_{2}$ e $\mathrm{FB}_{3}$ foram de $100,0 \%$, 91,8\% e $209,0 \%$, respectivamente. Contudo, não houve reatividade cruzada com hidrolisados de fumonisinas. A taxa de recuperação variou de $61 \%$ a $84 \%$ utilizando concentrações de $50 \mathrm{ng} / \mathrm{g}$ a $200 \mathrm{ng} / \mathrm{g}$, e a análise comparativa de milho naturalmente contaminado mostrou que o método é adequado para a triagem rápida de cereais e rações ${ }^{160}$.

Kim et al. ${ }^{164}$ analisaram a ocorrência de $\mathrm{FB}_{1}$ em amostras de alimentos derivados de milho provenientes de Seul, Coreia do Sul, utilizando um dc-ELISA comercial. O limite de detecção foi de 5,0 ng/g, e a taxa de recuperação de amostras contaminadas artificialmente com concentrações de 10 $\mathrm{ng} / \mathrm{g}$ a $1.000 \mathrm{ng} / \mathrm{g}$ de $\mathrm{FB}_{1}$ foi de $104 \%$, e, além disso, apresentou uma alta correlação com a CLAE $(0,992)$.

Quan et al. ${ }^{165}$ desenvolveram um ELISA quimioluminescente a fim de aumentar a sensibilidade do imunoensaio. Nesse imunoensaio, após a reação de competição utilizando anticorpo policlonal, foi adicionado um reagente quimioluminescente. O limite de detecção foi de 0,09 $\mu \mathrm{g} / \mathrm{L}, 10$ vezes mais baixo que o dc-ELISA convencional. A taxa de recuperação em milho foi de 93,66\% utilizando as concentrações de $100 \mu \mathrm{g}, 250 \mu \mathrm{g}$ e $500 \mu \mathrm{g}$ de $\mathrm{FB}_{1} / \mathrm{Kg}$.

Wang et al. ${ }^{166}$ desenvolveram um teste rápido de ic-ELISA baseado em anticorpo policlonal, para a detecção de fumonisinas em diversos grãos (milho, cevada, amendoim, arroz e sorgo). O limite de detecção foi de 0,5 $\mu \mathrm{g} / \mathrm{L}$, e a análise foi realizada em apenas 20 minutos.

Anticorpos policlonais para fumonisinas foram utilizados para o desenvolvimento de um dc-ELISA. O limite de deteç̧ão para a $\mathrm{FB}_{1}$ foi de 0,05 ng/ $\mathrm{mL}$, e a reatividade cruzada do anticorpo com a $\mathrm{FB}_{1}, \mathrm{FB}_{2}$ e $\mathrm{FB}_{3}$ foi de $100 \%$, $70 \%$ e $0,5 \%$. De 15 amostras analisadas (alimentos derivados de cereais e rações), 12 estavam contaminadas com concentrações que variaram de 2 $\mathrm{ng} / \mathrm{g}$ a $2.170 \mathrm{ng} / \mathrm{g}$, confirmadas por CLAE ${ }^{161}$.

Sheng et al. ${ }^{167}$ produziram um anticorpo monoclonal para o desenvolvimento de um ic-ELISA para a detecção de $\mathrm{FB}_{1}$ em milho. $\mathrm{O}$ anticorpo 
monoclonal apresentou reatividade cruzada com a $\mathrm{FB}_{2}$ e reatividade cruzada insignificante com outras micotoxinas. O limite de detecção foi 5,4 $\mu \mathrm{g} / \mathrm{Kg}$, e a taxa de recuperação a partir de amostras de milho contaminadas artificialmente com $\mathrm{FB}_{1}(100 \mu \mathrm{g} / \mathrm{Kg}$ a $500 \mu \mathrm{g} / \mathrm{Kg})$ variou de $101 \pm 7 \%$ a $107 \pm 4 \%$. A análise de amostras de milho naturalmente contaminadas pelo ic-ELISA foi comparado com o LC/MS e apresentou um coeficiente de correlação de 0,82 , indicando que o ic-ELISA pode ser utilizado para a triagem de amostras de milho, antes da confirmação por um método instrumental.

Alguns métodos imunocromatográficos foram desenvolvidos para a triagem rápida da contaminação por fumonisinas em cereais ${ }^{27,28,168,169}$.

Li et al. ${ }^{27}$ desenvolveram uma imunocromatografia baseada em anticorpo monoclonal conjugado com ouro para a deteç̧ão de fumonisinas $\left(\mathrm{FB}_{1}, \mathrm{FB}_{2}\right.$ e $\mathrm{FB}_{3}$ ) em milho, com um limite de detecção de $2,5 \mathrm{ng} / \mathrm{mL}$. As amostras de milho contaminadas artificialmente com fumonisinas $(2,5 \mathrm{ng} / \mathrm{mL}$ a $40 \mathrm{ng} /$ $\mathrm{mL}$ ) apresentaram uma boa correlação com LC/MS, indicando que o teste pode ser utilizado na avaliação semiquantitativa de fumonisinas in-situ.

Para a avaliação quantitativa, a intensidade das linhas teste presentes na membrana tem sido avaliada por meio de um leitor fotométrico para determinar a concentração de $\mathrm{FB}_{1}$ com base em uma curva de calibração. O limite de detecção para a $\mathrm{FB}_{1}$ foi de $5,23 \mathrm{ng} / \mathrm{mL}$, e o método apresentou uma boa correlação $(0,96)$ com o LC-MS/MS, indicando que além de ser um método rápido também pode ser utilizado para o monitoramento de $\mathrm{FB}_{1}{ }^{28}$.

Um dipstick comercial baseado em um imunoensaio competitivo indireto foi utilizado para a detecção qualitativa de fumonisinas e outras micotoxinas de Fusarium spp. (zearalenona, toxina T-2 e desoxinivalenol) em milho. Os extratos das amostras dos cereais foram adicionados em micropoços contendo os anticorpos antifumonisinas e antianticorpo conjugado a um complexo de proteína A-ouro, para a linha controle. O dipstick, contendo a linha teste composta de conjugado de $\mathrm{FB}_{1}$-albumina bovina foi imerso na amostra para que ocorresse a competição. A concentração miníma de fumonisinas detectada em milho foi de $3.200 \mu \mathrm{g} / \mathrm{Kg}, 80 \%$ da concentração máxima tolerada pela legislação europeia. Portanto, somente amostras com concentrações acima de $3.200 \mu \mathrm{g} / \mathrm{Kg}$ foram consideradas positivas. A detecção das micotoxinas em milho naturalmente contaminado apresentou uma boa correlação com o LC/MS, indicando que o dipstick é um método rápido (30 minutos) e de baixo custo para a triagem de micotoxinas em grãos ${ }^{32}$.

Nos últimos anos, os biossensores têm sido utilizados como uma alternativa promissora devido à alta sensibilidade, seletividade, simplicidade, facilidade de uso, baixo custo e, em alguns casos, a possibilidade de integração 
com dispositivos automatizados e portáteis ${ }^{19}$. Os biossensores mais utilizados para a detecção de micotoxinas são baseados em imunoensaio competitivo ou não competitivo acoplados a diferentes tipos de detectores. Imunossensores acoplados a detectores eletroquímicos ${ }^{170}$, ópticos ${ }^{171,172}$ e quimioluminescentes ${ }^{34}$ têm sido desenvolvidos para a detecção de fumonisinas.

Um biossensor, integrando um imunoensaio de fluxo lateral acoplado a um detector de quimioluminescência enzimática e a um dispositivo de carga-acoplada (DCA) de alta sensibilidade, foi desenvolvido para a detecção de fumonisinas $\left(\mathrm{FB}_{1}\right.$ e $\left.\mathrm{FB}_{2}\right)$ em milho. Nesse imunoensaio que utilizava tiras de fluxo lateral, uma solução contendo os anticorpos antifumonisinas, os anticorpos conjugados à enzima e extrato das amostras de milho foram aplicados em uma membrana de nitrocelulose, seguido de migração ao longo da membrana por capilaridade até atingir as zonas teste e controle. Após a adição de um substrato quimioluminescente, o sinal foi detectado por um DCA, e a determinação da concentração de fumonisinas realizada por meio dos fótons emitidos nas zonas teste e controle. O limite de detecção foi de 2,5 $\mu \mathrm{g}$ fumonisinas/L, e a faixa de trabalho de $25 \mu \mathrm{g}$ a $5.000 \mu \mathrm{g}$ de fumonisinas $/ \mathrm{Kg}$. A taxa de recuperação do método foi de $95 \%$ a $115 \%{ }^{34}$.

\subsection{PROTOCOLOS}

\subsubsection{ELISA competitivo indireto para deteç̣ão de exoantígeno de Fusarium spp. em milho ${ }^{54}$}

\section{Preparação das amostras}

- Misturar 10 g de amostra de milho triturado (granulometria de 50 mesh) a $90 \mathrm{~mL}$ de PBS (Salina tamponada com fosfato) 0,15 M estéril.

- Filtrar a suspensão de milho com papel filtro Whatman $n^{\circ} 1$.

- Armazenar o filtrado a $-20^{\circ} \mathrm{C}$ até o momento de uso.

\section{ELISA competitivo indireto}

- Sensibilizar a microplaca com $100 \mu \mathrm{L}$ de exoantígeno de F. verticillioides em tampão carbonato bicarbonato $0,2 \mathrm{M} \mathrm{pH} \mathrm{9,6,} \mathrm{a} 4$ ${ }^{\circ} \mathrm{C}$ por 16 horas.

- Lavar três vezes com PBS-Tween 20 0,05\% (PBS-T). 
- Bloquear a microplaca com $150 \mu \mathrm{L}$ de PBS-leite desnatado $1 \%$ por 3 horas a $25^{\circ} \mathrm{C}$.

- Lavar três vezes com PBS-T.

- Incubar com $50 \mu \mathrm{L}$ de soro imune anti-F. verticillioides diluído em PBS-leite desnatado $1 \%$ e $50 \mu \mathrm{L}$ do filtrado da amostra de milho por 16 horas a $4{ }^{\circ} \mathrm{C}$.

- Lavar com PBS-T.

- Incubar com $100 \mu \mathrm{L}$ de conjugado anti-IgG-peroxidase por 1,5 horas a $25{ }^{\circ} \mathrm{C}$.

- Lavar com PBS-T.

- Incubar com $100 \mu \mathrm{L}$ de solução de substrato $\left(\mathrm{H}_{2} \mathrm{O}_{2} /\right.$ 3,3',5,5'-tetrametilbenzidina) a $25{ }^{\circ} \mathrm{C}$.

- Adicionar $50 \mu \mathrm{L}$ de ácido sulfúrico $\left(\mathrm{H}_{2} \mathrm{SO}_{4}\right) 1 \mathrm{M}$.

- Determinar a absorvância (450 nm).

Observação: a concentração de exoantígeno utilizada na sensibilização da microplaca e as diluições do soro e do conjugado deverão ser previamente padronizadas.

\subsubsection{ELISA competitivo indireto para detecção de fumonisinas em milho ${ }^{22}$}

\section{Preparação das amostras}

- Misturar $10 \mathrm{~g}$ de amostra de milho triturado (granulometria de 50 mesh) com $30 \mathrm{~mL}$ de metanol: água $(3: 1, \mathrm{v} / \mathrm{v})$ e centrifugar $10.000 \times g$.

- Diluir o sobrenadante com PBS 0,15 M (é necessário padronizar a diluição de acordo com os níveis de contaminação).

\section{ELISA competitivo indireto}

- Sensibilizar a microplaca com o conjugado $\mathrm{FB}_{1}$-ovalbumina $(100 \mu \mathrm{L})$ em PBS a $4{ }^{\circ} \mathrm{C}$ por 16 horas.

- Lavar três vezes com PBS-Tween 20 0,05\%.

- Bloquear a microplaca com $150 \mu \mathrm{L}$ de PBS-leite desnatado 5\% por 16 horas a $4{ }^{\circ} \mathrm{C}$.

- Lavar três vezes com PBS-Tween $200,05 \%$ e adicionar $50 \mu \mathrm{L}$ de padrões de $\mathrm{FB}_{1}$ ou do extrato diluído das amostras de milho e $50 \mu \mathrm{L}$ 
de anticorpo monoclonal anti-FB $\mathrm{FB}_{1}$ em $\mathrm{PBS}$, incubar por 16 horas a $4{ }^{\circ} \mathrm{C}$.

- Lavar três vezes com PBS-Tween 20 0,05\% e adicionar $100 \mu \mathrm{L}$ de anticorpo anti-IgG-peroxidase, incubar a $25^{\circ} \mathrm{C}$ por 1 hora e lavar conforme descrito anteriormente.

- Adicionar $100 \mu \mathrm{L}$ de substrato $\left(\mathrm{H}_{2} \mathrm{O}_{2} / 3\right.$ 3,3',5,5'-tetrametilbenzidina). Após 45 minutos a $25^{\circ} \mathrm{C}$, bloquear a reação adicionando $50 \mu \mathrm{L}$ de $\mathrm{H}_{2} \mathrm{SO}_{4} 1 \mathrm{M}$ e determinar a absorvância a $450 \mathrm{~nm}$ (leitora de ELISA). Calcular a absorvância média das absorvâncias individuais obtidas de duplicata e expressar os resultados em porcentagens de ligação:

(Equação 24.1) Ligação $(\%)=\left(A^{+} / A^{-}\right) \times 100$

em que $A^{+}$é a absorvância média na presença de cada amostra ou padrão e $A^{-}$é a absorvância média na sua ausência. A concentração de fumonisinas é determinada utilizando uma curva padrão $\left(0,2 \mathrm{ng} / \mathrm{mL}\right.$ a $5,0 \mathrm{ng} / \mathrm{mL}$ de $\left.\mathrm{FB}_{1}\right)$ plotada em porcentagem de ligação contra a concentração de $\mathrm{FB}_{1}$ transformada em log.

Observação: a concentração de conjugado $\mathrm{FB}_{1}$-ovalbumina utilizada na sensibilização da microplaca e as diluições do anticorpo e do conjugado deverão ser previamente padronizadas.

\subsection{CONSIDERAC̣ÕES FINAIS}

Os métodos imunológicos para a triagem da contaminação de grãos, alimentos e rações por fungos toxigênicos e micotoxinas proporcionam análises com alta sensibilidade, precisão, rapidez e baixo custo. O imunoensaio ELISA para exoantígenos permite a detecção semiquantitativa de fungos toxigênicos. O ELISA é um dos métodos imunológicos mais utilizados para a detecção de micotoxinas; porém, as possíveis reações falso positivas impedem que esse método seja reconhecido como um método oficial pela Association of Official Analytical Chemists (AOAC), tornando necessária a confirmação dos resultados por métodos químicos. Métodos rápidos como a imunocromatografia e o dipstick reduzem consideravelmente o tempo da análise e contribuem para a avaliação qualitativa da contaminação de amostras de forma precisa. Atualmente há disponibilidade de kits comerciais baseados em ELISA, imunocromatografia e dispstick para a detecção das principais 
micotoxinas. Os biossensores constituem uma alternativa promissora para a detecção quantitativa in situ de fungos toxigênicos e micotoxinas em grãos com alta sensibilidade. Um dos desafios para o desenvolvimento de novos métodos para detecção de fungos toxigênicos e micotoxinas está atrelado à produção de anticorpos altamente específicos para a aplicação em dispositivos portáteis que permitam a análise in situ. O controle da qualidade de grãos, alimentos e rações depende da disponibilidade de métodos rápidos, sensíveis, confiáveis e de baixo custo. 


\section{REFERÊNCIAS}

1. Magan N, Olsen M. Mycotoxins in Food: Detection and Control. Cambridge: Woodhead Publishing Ltd; 2004.

2. Smith JEM, Moss O. Mycotoxins, formation, analysis and significance. Chichester: Wiley; 1985.

3. Council for Agricultural Science and Technology (CAST). Mycotoxins: risks in plants, animal and human systems. Task force report. Report n. 139. Ames: Iowa; 2003.

4. Ono EYS, Silva M, Hashimoto EH, Vizoni E, Kawamura O, Sugiura Y, Hirooka EY. Mycotoxicological quality evaluation of corn samples used by processing industries in the Northern region of Paraná State, Brazil. Food Addit Contam. 2008;25:1392-9.

5. Ross PF, Nelson PE, Richard JL, Osweiler GD, Rice LG, Plattner RD, Wilson TM. Production of fumonisins by Fusarium moniliforme and Fusarium proliferatum isolates associated with equine leukoencephalomalacia and a pulmonary edema syndrome in swine. Appl Environ Microbiol. 1990;56:3225-6.

6. Goto T, Wicklow DT, Ito Y. Aflatoxin and cyclopiazonic acid production by a sclerotium-producing Aspergillus tamarii strain. Appl Environ Microbiol. 1996;62:4036-8.

7. Klich MA, Mullaney EJ, Daly CB, Cary JW. Molecular and physiological aspects of aflatoxin and sterigmatocystin biosynthesis by Aspergillus tamarii and A. ochraceoroseus. Appl Microbiol Biotechnol. 2000;53:605-9.

8. Borutova R, Aragon YA, Nährer K, Berthiller F. Co-occurrence and statistical correlations between mycotoxins in feedstuffs collected in the Asia-Oceania in 2010. Anim Feed Sci Technol. 2012;178:190-7.

9. Queiroz VAV, Alves GLO, Conceição RRP, Guimarães LJ, Mendes SM, Ribeiro PEA, Costa RV. Occurrence of fumonisins and zearalenone in maize stored in family farm in Minas Gerais, Brazil. Food Control. 2012;28:83-6.

10. Rossi CN, Takabayashi CR, Ono MA, Bordini JG, Kawamura O, Vizoni E, Hirooka EY, Ono EYS. Assessment of exposure of broiler chicken in Brazil to mycotoxins through naturally contaminated feed. Food Sec. 2013;5:541-50.

11. Ono EYS, Ono MA, Funo FY, Medina AE, Oliveira TCRM, Kawamura O, Ueno Y, Hirooka EY. Evaluation of fumonisin-aflatoxin co-occurrence in Brazilian corn hybrids by ELISA. Food Addit Contam. 2001;18:719-29.

12. Food and Agriculture Organization of the United Nations (FAO). Worldwide regulations for mycotoxins in food and feed in 2003. Rome, Italy; 2004.

13. Brasil. Ministério da Agricultura. Portaria MA/SNAD/SFA n. 7. Brasília: Diário Oficial da República Federativa do Brasil; 1988 Nov 9; Seção I. p. 21968.

14. Brasil. Ministério da Saúde. Agência Nacional de Vigilância Sanitária (ANVISA). Resolução RDC n. 7. 2011 Feb 18. Dispõe sobre limites máximos tolerados (LMT) para 
micotoxinas em alimentos. Brasília: Diário Oficial da República Federativa do Brasil; 2011 Feb 22. Seção I. p. 72.

15. Pitt J, Hocking AD. Fungi and Food Spoilage. 3. ed. New York City: Springer; 2009. 16. Steenkamp ET, Wingfield BD, Coutinho TA, Zeller KA, Wingfield MJ, Marasas WFO, Leslie JF. PCR-based identification of MAT-1 and MAT-2 in the Gibberella fujikuroi species complex. Appl Environ Microbiol. 2000;66:4378-82.

17. Kolosova AY, Shim W, Yang Z, Eremin SA, Chung D. Direct competitive ELISA based on monoclonal antibody for detection of aflatoxin $B_{1}$ - stabilization of ELISA kit components and application to grain samples. Anal Bioanal Chem. 2006;384:286-94.

18. Valenta H. Chromatographic methods for the determination of ochratoxin A in animal and human tissues and fluids. J Chromatogr A. 1998;15:75-92.

19. Campàs M, Garibo D, Prieto-Simón B. Novel nanobiotechnological concepts in electrochemical biosensors for the analysis of toxins. Analyst. 2012;137:1055-67.

20. Gilbert J, Anklam E. Validation of analytical methods for determining mycotoxins in foodstuffs. Trends Analyt Chem. 2002;21:468-86.

21. Krska R, Molinelli A. Mycotoxin analysis: State of the art and future trends. Anal Bioanal Chem. 2007;387:145-8.

22. Ono EYS, Kawamura O, Ono MA, Ueno Y, Hirooka EY. A Comparative Study of Indirect Competitive ELISA and HPLC for fumonisin detection in corn of the State of Paraná, Brazil. Food Agric Immunol. 2000;12:5-14.

23. Zheng M, Richard J, Binder J. A review of rapid methods for the analysis of mycotoxins. Mycopathologia. 2006;161:261-73.

24. Hefle SL. Immunoassay fundamentals. Food Technol. 1995;49:102-7.

25. Lin HH, Cousin MA. Evaluation of enzyme-linked immunosorbent assay for detection of molds in foods. J Food Sci. 1987;52:1089-94.

26. Urusov AE, Zherdev AV, Dzantiev BB. Immunochemical methods of mycotoxin analysis (Review). Appl Biochem Microbiol. 2010;46:253-66.

27. Li YS, Zhou Y, Lu SY, Guo DJ, Ren HL, Meng XM, Zhi BH, Lin C, Wang Z, Lia XB Liu ZS. Development of a one-step test strip for rapid screening of fumonisins $B_{1}$, $B_{2}$ and $\mathrm{B}_{3}$ in maize. Food Control. 2012;24:72-7.

28. Wang YK, Yan YX, Ji WH, Wang H, Li SQ, Zou Q, Sun JH. Rapid simultaneous quantification of Zearalenone and Fumonisin $\mathrm{B}_{1}$ in corn and wheat by lateral flow dual immunoassay. J Agric Food Chem. 2013;61:5031-6.

29. Goryacheva IY, Saeger SD, Eremin SA, Van Peteghem C. Immunochemical methods for rapid mycotoxin detection: Evolution from single to multiple analyte screening: A review. Food Addit Contam. 2007;24:1169-83.

30. Delmulle BS, De Saeger SMDG, Sibanda L, Barna-Vetro I, Van Peteghem CH. Development of an immunoassay-based lateral flow dipstick for the rapid detection of Aflatoxin $B_{1}$ in pig feed. J Agric Food Chem. 2005;53:3364-8. 
31. Krska R, Molinelli A. Rapid test strips for analysis of mycotoxins in food and feed. Anal Bioanal Chem. 2009;393:67-71.

32. Lattanzio VMT, Nivarlet N, Lippolis V, Gatta SD, Huet AC, Delahaut P, Granier B, Visconti A. Multiplex dipstick immunoassay for semi-quantitative determination of Fusarium mycotoxins in cereals. Anal Chim Acta. 2012;718:99-108.

33. Lattanzio VMT, Von Holst C, Visconti A. Experimental design for in-house validation of a screening immunoassay kit. The case of a multiplex dipstick for Fusarium mycotoxins in cereals. Anal Bioanal Chem. 2013;405:7773-82.

34. Mirasoli M, Buragina A, Dolci LS, Simoni P, Anfossi L, Giraudi G, Roda A. Chemiluminescence-based biosensor for fumonisins quantitative detection in maize samples. Biosens Bioelectron. 2012;32:283-7.

35. Diener UL, Cole RJ, Sanders TH, Payne GA, Lee SL, Klich ML. Epidemiology of aflatoxin formation by Aspergillus flavus. Ann Rev Phytopathol. 1987;25:249-70.

36. Diener UL, Davis ND. Limiting temperature and relative humidity for growth and production of aflatoxin and free fatty acids by Aspergillus flavus in sterile peanuts. J Am Oil Chem Soc. 1967;44:159-63.

37. Frisvad JC, Skouboe P, Samson RA. Taxonomic comparison of three different groups of aflatoxin producers and a new efficient producer of aflatoxin $\mathrm{B}_{1}$, sterigmatocystin and 3-O-methylsterigmatocystin, Aspergillus rambellii sp. nov. Syst. Appl Microbiol. 2005;28:442-53.

38. Varga J, Frisvad JC, Samson RA. Two new aflatoxin producing species, and an overview of Aspergillus section Flavi. Stud Mycol. 2011;69:57-80.

39. Warnock DW. Use of immunofluorescence to detect mycelium of Alternaria, Aspergillus and Penicillium in barley grains. Trans Br Mycol Soc. 1973; 61: 547-52.

40. Tsai G-J, Yu S-C. Detecting Aspergillus parasiticus in cereals by an enzyme-linked immunosorbent assay. Int J Food Microbiol. 1999;50:181-9.

41. Yong RK, Cousin MA. Detection of moulds producing aflatoxins in maize and peanuts by an immunoassay. Int J Food Microbiol. 2001;65:27-38.

42. Lin HH, Lister RM, Cousin MA. Enzyme-linked immunosorbent assay for detection of mould in tomato puree. J Food Sci. 1986;51:180-3, 192.

43. Tsai GJ, Cousin MA. Enzyme-linked immunosorbent assay for detection of molds in cheese and yogurt. J Dairy Sci. 1990;73:3366-78.

44. Shapira R, Paster N, Menasherow M, Eyal O, Mett A, Meiron T, Kuttin E, Salomon R. Development of polyclonal antibodies for detection of aflatoxigenic molds involving culture filtrate and chimeric proteins expressed in Escherichia coli. Appl Environ Microbiol. 1997;63:990-5.

45. Villamizar RA, Maroto A, Rius FX. Rapid detection of Aspergillus flavus in rice using biofunctionalized carbon nanotube field effect transistors. Anal Bioanal Chem. 2011;399:119-26. 
46. Villamizar RA, Braun J, Gompf B, Dressel M, Rius FX. Morphological and electrical characteristics of biofunctionalized layers on carbon nanotubes. Biosens Bioelectron. 2009;25:161-6.

47. Sun X, Yan L, Tang Y, Zhang Y. A rapid and specific immunosensor for the detection of aflatoxigenic Aspergilli. Eur Food Res Technol. 2012;234:1013-21.

48. Thiel PG, Marasas WFO, Sydenham EW, Shephard GS, Gelderblom WCA, Nieuwenhuis JJ. Survey of fumonisin production by Fusarium species. Appl Environ Microbiol. 1991;57:1089-93.

49. Gelderblom WC, Jackiewicz K, Marasas WF, Thiel PG, Horak RM, Vleggaar R, Kriek NP. Fumonisins - novel mycotoxins with cancer-promoting activity produced by Fusarium moniliforme. Appl Environ Microbiol. 1988;54:1806-11.

50. Rheeder JP, Marasas WFO, Thiel PG, Sydenham EW, Shephard GG, Schalkwyk DJV. Fusarium moniliforme and fumonisins in corn in relation to human esophageal cancer in Transkei. Phytopathology. 1992;82:353-7.

51. Weibking T, Ledoux DR, Bermudez AJ, Turk JR, Rottinghaus GE, Wang E, Merrill AH. Effects of feeding Fusarium moniliforme culture material, containing known levels of fumonisin $\mathrm{B}_{1}$, on the young broiler chick. Poult Sci. 1993;72:456-66.

52. Chala A, Weinert J, Wolf GA. An integrated approach to the evaluation of the efficacy of fungicides against Fusarium culmorum, the cause of Head Blight of wheat. J Phytopathol. 2003;151:673-8.

53. Hill N, Schwarz P, Dahleen LS, Neate SM, Horsley R, Glenn AE, O’Donnell K. ELISA analysis for Fusarium in barley: Development of methodology and field assessment. Crop Sci. 2006;46:2636-42.

54. Meirelles PG, Ono MA, Ohe MCT, Maroneze DM, Itano EN, Garcia GT, Sugiura Y, Ueno Y, Hirooka EY, Ono EYS. Detection of Fusarium sp. contamination in corn by enzyme-linked immunosorbent assay. Food Agric Immunol. 2006;17:79-89.

55. Miedaner T, Beyer W, Höxter H, Geiger HH. Growth stage specific resistance of winter rye to Microdochium nivale and Fusarium spp. in the field assessed by immunological methods. Phytopathology. 1994;85:416-21.

56. Miedaner T, Schneider B, Oettler G, Rohde S, Rabenstein F. Estimation of deoxynivalenol (DON) content by symptom rating and exoantigen content for resistance selection in wheat and triticale. Euphytica. 2004;139:123-32.

57. Rohde S, Rabenstein F. Standardization of an indirect PTA-ELISA for detection of Fusarium spp. in infected grains. Mycotoxin Res. 2005;21:100-4.

58. Sliková S, Sudyová V, Martinek P, Polisenská I, Gregová E, Mihálik D. Assessment of infection in wheat by Fusarium protein equivalent levels. Eur J Plant Pathol. 2009;124:163-70. 
59. Gan Z, Marquardt R, Abramson D, Clear RM. The characterization of chicken antibodies raised against Fusarium spp. by enzyme-linked immunosorbent assay and immunoblotting. Int J Food Microbiol. 1997;38:191-200.

60. Kaufman L, Standard PG. Specific and rapid identification of medically important fungi by exoantigen detection. Annu Rev Microbiol. 1987;41:209-25.

61. Notermans S, Heuvelman CJ. Immunological detection of moulds in food by using the enzyme-linked immunosorbent assay (ELISA); preparation of antigens. Int J Food Microbiol. 1985;2:247-58.

62. De Ruiter GA, Notermans SHW, Rombouts FM. New methods in food mycology. Trends Food Sci Technol. 1993;4:91-7.

63. Abramson D, Gan Z, Clear RM, Gilbert J, Marquardt RR. Relationships among deoxynivalenol, ergosterol and Fusarium exoantigens in Canadian hard and soft wheat. Int J Food Microbiol. 1998;45:217-24.

64. Bottalico A, Perrone G. Toxigenic Fusarium species and mycotoxins associated with head blight in small-grain cereals in Europe. Eur J Plant Pathol. 2002; 108: 611-24.

65. Logrieco A, Mulè G, Moretti A, Bottalico A. Toxigenic Fusarium species and mycotoxins associated with maize ear rot in Europe. Eur J Plant Pathol. 2002;108:597-609.

66. Iyer MS, Cousin MA. Immunological detection of Fusarium species in cornmeal. J Food Prot. 2003;66:451-6.

67. Biazon L, Meirelles PG, Ono MA, Itano EN, Taniwaki M, Sugiura Y, Ueno Y, Hirooka EY, Ono EYS. Development of polyclonal antibodies against Fusarium verticillioides exoantigens. Food Agric Immunol. 2006;17:69-77.

68. Hill NS, Neate SM, Cooper B, Horsley R, Schwarz P, Dahleen LS, Smith KP, O’Donnell K, Reeves J. Comparison of ELISA for Fusarium, visual screening, and deoxynivalenol analysis of Fusarium Head Blight for barley field nurseries. Crop Sci. 2008;48:1389-98. 69. Grimm C, Geisen R. A PCR-ELISA for detection of potential fumonisin producing Fusarium species. Lett Appl Microbiol. 1998;26:456-62.

70. Poljak M, Seme K. Rapid detection and typing of human papillomaviruses by consensus polymerase chain reaction and enzyme-linked immunosorbent assay. J Virol Methods. 1996;56:231-8.

71. Whitby JE, Heaton PR, Whitby HE, O'Sullivan E, Johnstone P. Rapid detection of rabies and rabies-related viruses by RT-PCR and enzyme-linked immunosorbent assay. J Virol Methods. 1997;69:63-72.

72. Blount W. Turkey “X” disease. Turkeys. 1961;9:52-58, 61, 67.

73. Asao T, Buchi G, Abdel-Kader MM, Chang SB, Wick EL, Wogan GN. Aflatoxins B and G. J Am Chem. Soc. 1963;85:1706-7.

74. Hartley RD, Nesbitt BF, O'Kelly J. Toxic metabolites of Aspergillus flavus. Nature. 1963;198:1056-8. 
75. Hussein HS, Brasel JM. Toxicity, metabolism, and impact of mycotoxins on humans and animals. Toxicology. 2001;167:101-34.

76. Bennet JW, Klich M. Mycotoxins. Clin Microbiol Rev. 2003;16:497-516.

77. Van Egmond HP. Current situation on regulations for mycotoxins. Overview of tolerances and status of standard method of sampling and analysis. Food Addit Contam. 1989;6:139-88.

78. Benasutti M, Ejadi S, Whitlow MD, Loechler EL. Mapping the binding site of aflatoxin $B_{1}$ in DNA: Systematic analysis of the reactivity of aflatoxin $B_{1}$ with guanines in different DNA sequences. Biochemistry. 1988;27:472-81.

79. Croy RG, Essigmann JM, Reinhold VN, Wogan GN. Identification of the principal aflatoxin $\mathrm{B}_{1}$-DNA adduct formed in vivo in rat liver. Proc Natl Acad Sci USA. 1978;75:1745-9.

80. Croy RG, Wogan GN. Quantitative comparison of covalent aflatoxin-DNA adducts formed in rat and mouse livers and kidneys. J Natl Cancer Inst. 1981;66:761-8.

81. Essigmann JM, Croy RG, Nadzan AM, Busby WF, Reinhold VN, Büchi G, Wogan GN. Structural identification of the major DNA adduct formed by aflatoxin $\mathrm{B}_{1}$ in vitro. Proc Natl Acad Sci USA. 1977;74:1870-4.

82. Aguilar F, Hussain SP, Cerutti P. Aflatoxin $B_{1}$ induces the transversion of $G \rightarrow T$ in codon 249 of the p53 tumor suppressor gene in human hepatocytes. Proc Natl Acad Sci USA. 1993;90:8586-90.

83. Bressac B, Kew M, Wands J, Ozturk M. Selective G to T mutations of p53 gene in hepatocellular carcinoma from southern Africa. Nature. 1991;350:429-31.

84. Cariello NF, Cui L, Skopek TR. In vitro mutational spectrum of aflatoxin $\mathrm{B}_{1}$ in the human hypoxanthine guanine phosphoribosyltransferase gene. Cancer Res. 1994;54:4436-41.

85. Harris CC, Hollstein M. Clinical implications of the p53 tumor-suppressor gene. N Engl J Med. 1993;329:1318-27.

86. Puisieux A, Lim S, Groopman J, Ozturk M. Selective targeting of p53 gene mutational hotspots in human cancers by etiologically defined carcinogens. Cancer Res. 1991;51:6185-9.

87. Guindon KA, Bedard LL, Massey TE. Elevation of 8-hydroxydeoxyguanosine in DNA from isolated mouse lung cells following in vivo treatment with aflatoxin $\mathrm{B}_{1}$. Toxicol Sci. 2007;98:57-62.

88. Azziz-Baumgartner E, Lindblade K, Gieseker K, Rogers HS, Kieszak S, Njapau H, Schleicher R, Mccoy LF, Misore A, DeCock K, Rubin C, Slutsker L, Aflatoxin Investigative Group. Case-control study of an acute aflatoxicosis outbreak, Kenya, 2004. Environ Health Perspect. 2005;113:1779-83.

89. Krishnamachari KA, Nagarajan V, Bhat RV, Tilak TBG. Hepatitis due to aflatoxicosis: An outbreak in Western India. Lancet. 1975;1:1061-3. 
90. Becroft DM, Webster DR. Aflatoxins and Reye's disease. Br Med J. 1972;4:117. 91. Hendrickse RG. The influence of aflatoxins on child health in the tropics with particular reference to kwashiorkor. Trans R Soc Trop Med Hyg. 1984;78:427-35. 92. Shank RC, Bourgeois CH, Keschamras N, Chandavimol P. Aflatoxins in autopsy specimens from Thai children with an acute disease of unknown aetiology. Food Cosmet Toxicol. 1971;9:501-7.

93. Kelly JD, Eaton DL, Guengerich FP, Coulombe RA. Aflatoxin $\mathrm{B}_{1}$ activation in human lung. Toxicol Appl Pharmacol. 1997;144:88-95.

94. Qian GS, Ross RK, Yu MC, Yuan JM, Gao YT, Henderson BE, Wogan GN, Groopman JD. A follow-up study of urinary markers of aflatoxin exposure and liver cancer risk in Shanghai, People's Republic of China. Cancer Epidemiol Biomarkers Prev. 1994;3:3-10. 95. Ross RK, Yuan JM, Yu MC, Wogan GN, Gian GS, Tu JT, Groopman JD, Gao YT, Henderson BE. Urinary aflatoxin biomarkers and risk of hepatocellular carcinoma. Lancet. 1992;339:943-6.

96. Turner PC, Moore SE, Hall AJ, Prentice AM, Wild CP. Modification of immune function through exposure to dietary aflatoxin in Gambian Children. Environ Health Perspect. 2003;111:217-20.

97. Chen SY, Chen CJ, Tsai WY, Ahsan H, Liu TY, Lin JT, Santella RM. Associations of plasma aflatoxin $\mathrm{B}_{1}$-Albumin adduct level with plasma selenium level and genetic polymorphisms of Glutathione S-Transferase M1 and T1. Nutr Cancer. 2000;38:179-85. 98. Neldon-Ortiz DL, Qureshi MA. Direct and microsomal activated aflatoxin $B_{1}$ exposure and its effects on turkey peritoneal macrophage functions in vitro. Toxicol Appl Pharmacol. 1991;109:432-42.

99. Smith EE, Kubena LF, Braithwaite CE, Harvey RB, Phillips TD, Reine AH. Toxicological evaluation of aflatoxin and cyclopiazonic acid in broiler chickens. Poult Sci. 1992;71:1136-44.

100. Harvey RB, Huff WE, Kubena LF, Corrier DE, Phillips TD. Progression of aflatoxicosis in growing barrows. Am J Vet Res. 1988;49:482-7.

101. Newberne PM, Russo R, Wogan GN. Acute toxicity of aflatoxin $B_{1}$ in the $\operatorname{dog}$. Pathol Vet. 1966;3:331-40.

102. Wogan GN, Paglialunga S, Newberne PM. Carcinogenic effects of low dietary levels of aflatoxin $\mathrm{B}_{1}$ in rats. Food Cosmet Toxicol. 1974;12:681-5.

103. Applebaum RS, Brackett RE, Wiseman DW, Marth EH. Response of dairy cows to dietary aflatoxin: feed intake and yield, toxin content, and quality of milk of cows treated with pure and impure aflatoxin. J Dairy Sci. 1982;65:1503-8.

104. Helferich WG, Garrett WN, Hsieh DPH, Baldwin RL. Feedlot performance and tissue residues of cattle consuming diets containing aflatoxins. J Anim Sci. 1986;62:691-6. 
105. Fernández A, Belío R, Ramos JJ, Sanz MC, Sáez T. Aflatoxins and their metabolites in the tissues, faeces and urine from lambs feeding on an aflatoxin-contaminated diet. J Sci Food Agric. 1997;74:161-8.

106. Fernández A, Hernández M, Verde MT, Sanz M. Effect of aflatoxin on performance, hematology, and clinical immunology in lambs. Can J Vet Res. 2000;64:53-8.

107. IARC-International Agency for Research on Cancer. Some mycotoxins - Aflatoxins. IARC Monogr Eval Carcinog Risks Hum. 2002;82:171-301.

108. Squire RA. Ranking animal carcinogens: A proposed regulatory approach. Science. 1981;214:877-80.

109. Wogan GN, Edwards GS, Newberne PM. Structure-activity relationships in toxicity and carcinogenicity of aflatoxins and analogs. Cancer Res. 1971;31:1936-42.

110. Commission Regulation (EU). n. 574/2011, amending Annex I to Directive 2002/32/ EC of the European Parliament and of the Council as regards maximum levels for nitrite, melamine, Ambrosio spp. and carry-over of certain coccidiostats and histomonostats and consolidating Annexes I and II thereto Official Journal of the European Union, L159/7-L159/24. 2011 Jun 16.

111. Brasil. Portaria n. 130. 2006 May 24. O Ministério da Agricultura, Pecuária e Abastecimento institui o Grupo de Trabalho sobre Micotoxinas em produtos destinados à alimentação animal. Brasília: Diário Oficial da União da República Federativa do Brasil, 2006 May 25. Seção II. p. 5.

112. Comissão Europeia. Regulamento (UE) n. 165/2010. 2010 Feb 26. Altera o Regulamento (CE) n. 1881/2006, que fixa os teores máximos de certos contaminantes presentes nos géneros alimentícios, no que diz respeito às aflatoxinas. Jornal Oficial da União Europeia; 2010. L50/8-L50/12.

113. Asis R, Di Paola RD, Aldao MAJ. Determination of aflatoxin $B_{1}$ in highly contaminated peanut samples using HPLC and ELISA. Food Agric Immunol. 2002;14:201-8.

114. Edupuganti SR, Edupuganti OP, Hearty S, O’Kennedy R. A highly stable, sensitive, regenerable and rapid immunoassay for detecting aflatoxin $\mathrm{B}_{1}$ in corn incorporating covalent $\mathrm{AFB}_{1}$ immobilization and a recombinant Fab antibody. Talanta. 2013;115:329-35.

115. Guan D, Li P, Zhang Q, Zhang W, Zhang D, Jiang J. An ultra-sensitive monoclonal antibody-based competitive enzyme immunoassay for aflatoxin $\mathrm{M}_{1}$ in milk and infant milk products. Food Chem. 2011;125:1359-64

116. Kawamura O, Nagayama S, Sato S, Ohtani K, Ueno I, Ueno Y. A monoclonal antibody-based enzyme-linked immunosorbent assay for aflatoxin $\mathrm{B}_{1}$ in peanut products. Mycotoxin Res. 1988;4:75-88.

117. Lipigorngoson S, Ali N, Yoshizawa T. Limited survey for aflatoxin contamination of rice imported into Japan. Micotoxins. 2003;53:95-101. 
118. Liu BH, Hsu YT, Lu CC, Yu FY. Detecting aflatoxin $B_{1}$ in foods and feeds by using sensitive rapid enzyme-linked immunosorbent assay and gold nanoparticle immunochromatographic strip. Food Control. 2013;30:184-9.

119. Radoi A, Targa M, Prieto-Simon B, Marty J-L. Enzyme-linked immunosorbent Assay (ELISA) based on superparamagnetic nanoparticles for aflatoxin $\mathrm{M}_{1}$ detection. Talanta. 2008;77:138-43.

120. Rossi CN, Takabayashi CR, Ono MA, Saito GH, Itano EN, Kawamura O, Hirooka EY, Ono EYS. Immunoassay based on monoclonal antibody for aflatoxin detection in poultry feed. Food Chem. 2012;132:2211-6.

121. Wang JJ, Liu BH, Hsu YT, Yu FY. Sensitive competitive direct enzyme-linked immunosorbent assay and gold nanoparticle immunochromatographic strip for detecting aflatoxin $M_{1}$ in milk. Food Control. 2011;22:964-9.

122. Li X, Li P, Zhang Q, Li R, Zhang W, Zhang Z, Ding X, Tang X. Multi-component immunochromatographic assay for simultaneous detection of aflatoxin $\mathrm{B}_{1}$, ochratoxin $\mathrm{A}$ and zearalenone in agro-food. Biosens Bioelectron. 2013;49:426-32.

123. Xiulan S, Xiaolian Z, Jian T, Xiaohong G, Jun Z, Chu FS. Development of an immunochromatographic assay for detection of aflatoxin $B_{1}$ in foods. Food Control. 2006;17:256-62.

124. Zhang D, Li P, Liu W, Zhao L, Zhang Q, Zhang W, Ding X, Wang J. Development of a detector-free semiquantitative immunochromatographic assay with major aflatoxins as target analytes. Sens Actuators B Chem. 2013;185:432-7.

125. Zhang D, Li P, Yang Y, Zhang Q, Zhang W, Xiao Z, Ding X. A high selective immunochromatographic assay for rapid detection of aflatoxin $B_{1}$. Talanta. 2011;85:736-42.

126. Zhang D, Li P, Zhang Q, Zhang W. Ultrasensitive nanogold probe-based immunochromatographic assay for simultaneous detection of total aflatoxins in peanuts. Biosens Bioelectron. 2011;26:2877-82.

127. Tang D, Sauceda JC, Lin Z, Ott S, Basova E, Goryacheva I, Biselli S, Lin J, Niessner R, Knopp D. Magnetic nanogold microspheres-based lateral-flow immunodipstick for rapid detection of aflatoxin $B_{2}$ in food. Biosens Bioelectron. 2009;25:514-8.

128. Ammida NHS, Micheli L, Palleschi G. Electrochemical immunosensor for determination of aflatoxin $B_{1}$ in barley. Anal Chim Acta. 2004;520:159-64.

129. Bacher G, Pal S, Kanungo L, Bhand S. A label-free silver wire based impedimetric immunosensor for detection of aflatoxin $M_{1}$ in milk. Sens Actuators B Chem. 2012;168:223-30.

130. Masoomi L, Sadeghi O, Banitaba MH, Shahrjerdi A, Davarani SSH. A nonenzymatic nanomagnetic electro-immunosensor for determination of Aflatoxin $\mathrm{B}_{1}$ as a model antigen. Sens Actuators B Chem. 2013;177:1122-7. 
131. Micheli L, Grecco R, Badea M, Moscone D, Palleschi G. An electrochemical immunosensor for aflatoxin $\mathrm{M}_{1}$ determination in milk using screen-printed electrodes. Biosens Bioelectron. 2005;21:588-96.

132. Sapsford KE, Taitt CR, Fertig S, Moore MH, Lassman ME, Maragos CM, ShriverLake LC. Indirect competitive immunoassay for detection of aflatoxin $\mathrm{B}_{1}$ in corn and nut products using the array biosensor. Biosens Bioelectron. 2006;21:2298-305.

133. Singh C, Srivastava S, Ali MA, Gupta TK, Sumana G, Srivastava A, Mathur RB, Malhotra BD. Carboxylated multiwalled carbon nanotubes based biosensor for aflatoxin detection. Sens Actuators B Chem. 2013;185:258-64.

134. Tan Y, Chu X, Shen GL, Yu RQ. A signal-amplified electrochemical immunosensor for aflatoxin $B_{1}$ determination in rice. Anal Biochem. 2009;387:82-6.

135. Parker CO, Tothill IE. Development of an electrochemical immunosensor for aflatoxin $M_{1}$ in milk with focus on matrix interference. Biosens Bioelectron. 2009;24:2452-7.

136. Benzuidenhout SC, Gorst RMMA, Marasas WFO, Spiteller G, Vleggaar R, Gelderblom, WCA. Structure elucidation of the fumonisins, mycotoxins from Fusarium moniliforme. J Chem Soc Chem Commun. 1988;11:743-5.

137. Rheeder JP, Marasas WFO, Vismer HF. Production of Fumonisin Analogs by Fusarium Species. Appl Environ Microbiol. 2002;68:2101-5.

138. Marasas WF. Fumonisins: history, world-wide occurrence and impact. Adv Exp Med Biol. 1996;392:1-17.

139. Plattner RD, Weisleder D, Shackelford DD, Peterson R, Powell RG. A new fumonisin from solid cultures of Fusarium moniliforme. Mycopathologia. 1992;117:23-8.

140. Merrill AH Jr, Sullards MC, Wang E, Voss KA, Riley RT. Sphingolipid metabolism: roles in signal transduction and disruption by fumonisins. Environ Health Perspect. 2001;109:283-9.

141. Riley RT, Enongene E, Voss KA, Norred WP, Meredith FI, Sharma RP, Spitsbergen J, Williams DE, Carlson DB, Merrill AH Jr. Sphingolipid perturbations as mechanisms for fumonisin carcinogenesis. Environ Health Perspect. 2001;109:301-8.

142. Voss KA, Smith GW, Haschek WM. Fumonisins: toxicokinetics, mechanism of action and toxicity. Anim Feed Sci Technol. 2007;137:299-325.

143. Merrill AH Jr, Wang E, Gilchrist DG, Riley RT. Fumonisins and other inhibitors of de novo sphingolipid biosynthesis. Adv Lipid Res. 1993;26:215-34.

144. Merrill AH Jr, Wang E, Vales TR, Smith ER, Schroeder JJ, Menaldino DS, Alexander C, Crane HM, Xia J, Liotta DC, Meredith FI, Riley RT. Fumonisin toxicity and sphingolipid biosynthesis. Adv Exp Med Biol. 1996;392:297-306.

145. Riley RT, Voss KA, Norred WP, Sharma RP, Wang E, Merrill AH. Fumonisin: mechanism of mycotoxicity. Rev Med Vet. 1998;149:617-26. 
146. Wang E, Norred WP, Bacon CW, Riley RT, Merrill AHJr. Inhibition of sphingolipid biosynthesis by fumonisins: Implications for diseases associated with Fusarium moniliforme. J. Biol. Chem. 1991;266:14486-90.

147. Marasas WFO, Kellerman TS, Gelderblom WCA, Coetzer JAW, Thiel PG, Van der Lugt JJ. Leukoencephalomalacia in a horse induced by fumonisin $\mathrm{B}_{1}$ isolated from Fusarium moniliforme. Onderstepoort J Vet Res.1988;55:197-203.

148. Ross PF, Wilson TM, Owens DL, Nelson HA, Richard JL. Concentrations of fumonisin $B_{1}$ in feeds associated with animal health problems. Mycopathologia. 1991;114:129-35.

149. Gelderblom WCA, Jaskiewicz K, Marasas WFO, Thiel PG. Toxicity and carcinogenicity of the Fusarium moniliforme metabolite, fumonisin $\mathrm{B}_{1}$, in rats. Carcinogenesis. 1991;12:1247-51.

150. Howard PC, Eppley RM, Stack ME, Warbritton A, Voss KA, Lorentzen RJ, Kovach RM, Bucci TJ. Fumonisin $B_{1}$ carcinogenicity in a two-year feeding study using F344 rats and B6C3F(1) mice. Environ Health Perspect. 2001;109:277-82.

151. Ledoux DR, Brown TP, Weibking TS, Rottinghaus GE. Fumonisin toxicity in broiler chicks. J. Vet. Diagn. Invest. 1992;4:330-3.

152. Sydenham EW, Thiel PG, Marasas WFO, Shephard GS, Van Schalkwyk DJ, Koch KR. Natural occurrence of some Fusarium mycotoxins in corn from low and high esophageal cancer prevalence areas of the Transkei, Southern Africa. J Agric Food Chem. 1990;38:1900-3.

153. Ueno Y, Iijima K, Wang SD, Sugiura Y, Sekijima M, Tanaka T, Chen C, Yu SZ. Fumonisins as a possible contributory risk factor for primary liver cancer: A 3-year study of corn harvest in Haimen, China, by HPLC and ELISA. Food Chem Toxicol. 1997;35:1143-50.

154. Cifuentes G. Perfil epidemiologico de las anomalias del tubo neural en Guatemala, durante el anõ 2000 [Tese de Doutorado]. Guatemala City: Universidad San Carlos de Guatemala School of Medicine; 2002.

155. Gelineau-van Waes J, Starr L, Maddox J, Aleman F, Voss KA, Wilberding J, Riley RT. Maternal fumonisin exposure and risk for neural tube defects: mechanisms in an in vivo mouse model. Birth Defects Res A Clin Mol Teratol. 2005;73:487-97.

156. Missmer SA, Suarez L, Felkner M, Wang E, Merrill AHJr, Rothman J, Hendricks KA. Exposure to fumonisins and the occurence of neural tube defects along the TexasMexico boarder. Environ. Health Perspect. 2006;114:237-41.

157. Comissão Europeia. Recomendação da comissão de 17 de Agosto de 2006 sobre a presença de desoxinivalenol, zearalenona, ocratoxina A, toxinas T-2 e HT-2 e fumonisinas em produtos destinados à alimentação animal. Jornal Oficial da União Europeia; L 229/7-L 229/9; 2006. 
158. Comissão Europeia. Regulamento (CE) n. 1126/2007 da Comissão de 28 de Setembro de 2007 que altera o Regulamento (CE) n. 1881/2006 que fixa os teores máximos de certos contaminantes presentes nos gêneros alimentícios, no que se refere às toxinas do Fusarium no milho e nos produtos à base de milho. Jornal Oficial da União Europeia; 2007. L255/14-L255/17.

159. Azcona-Olivera JI, Abouzied MM, Plattner RD, Pestka JJ. Production of monoclonal antibodies to the mycotoxins fumonisins $\mathrm{B}_{1}, \mathrm{~B}_{2}$, and $\mathrm{B}_{3}$. J Agric Food Chem. 1992;40:531-4.

160. Barna-vetró I, Szabó E, Fazekas B, Solti L. Development of a sensitive ELISA for the determination of fumonisin $B_{1}$ in cereals. J Agric Food Chem. 2000;48:2821-5.

161. Shiu CM, Wang JJ, Yu FY. Sensitive enzyme-linked immunosorbent assay and rapid one-step immunochromatographic strip for fumonisin $\mathrm{B}_{1}$ in grain-based food and feed samples. J Sci Food Agric. 2010;90:1020-6.

162. Sydenham EW, Shephard GS, Thiel PG, Bird C, Miller BM. Determination of fumonisins in corn: evaluation of competitive immunoassay and HPLC techniques. J Agric Food Chem. 1996;44:159-64.

163. Yeung JM, Prelusky DB, Savard ME, Dang BDM, Robinson LA. Sensitive immunoassay for fumonisin $B_{1}$ in corn. J Agric Food Chem. 1996;44:3582-6.

164. Kim EK, Shon DH, Chung SH, Kim YB. Survey for fumonisin $B_{1}$ in Korean cornbased food products. Food Addit Contam. 2002;19:459-64.

165. Quan Y, Zhang Y, Wang S, Lee N, Kennedy IR. A rapid and sensitive chemiluminescence enzyme-linked immunosorbent assay for the determination of fumonisin $\mathrm{B}_{1}$ in food samples. Anal Chim Acta. 2006;580:1-8.

166. Wang S, Quan Y, Lee N, Kennedy IR. Rapid determination of fumonisin $B_{1}$ in food samples by enzyme-linked immunosorbent assay and colloidal gold immunoassay. J Agric Food Chem. 2006;54:2491-5.

167. Sheng Y, Jiang W, De Saeger S, Shen J, Zhang S, Wang Z. Development of a sensitive enzyme-linked immunosorbent assay for the detection of fumonisin $\mathrm{B}_{1}$ in maize. Toxicon. 2012;60:1245-50.

168. Paepens C, De Saeger S, Sibanda L, Barna-Vetró I, Léglise I, Van Hove F, Van Peteghem C. A flow-through enzyme immunoassay for the screening of fumonisins in maize. Anal Chim Acta. 2004;523:229-235.

169. Wang YK, Shi YB, Zou Q, Sun JH, Chen ZF, Wang H, Li SQ, Yan YX. Development of a rapid and simultaneous immunochromatographic assay for the determination of zearalenone and fumonisin $B_{1}$ in corn, wheat and feedstuff samples. Food control. 2013;31:180-8.

170. Kadir MKA, Tothill IE. Development of an electrochemical immunosensor for fumonisins detection in foods. Toxins. 2010;2:382-98. 
171. Mullet W, Lai EPC, Yeung JM. Immunoassay of fumonisins by a surface plasmon resonance biosensor. Anal Biochem. 1998;258:161-7.

172. Thompson VS, Maragos CM. Fiber-Optic Immunosensor for the detection of fumonisin $B_{1}$. J Agric Food Chem. 1996;44:1041-6. 
